\title{
Evaluación in vitro de la capacidad biorremediadora de hongos filamentosos sobre petróleo crudo
}

\author{
Bioremediative Capacity Evaluation in vitro of the filamentous fungi on \\ crude oil
}

Claudia Cristina Bedoya Ciro ${ }^{1}$, Luis Hernando Estupiñan $\mathbf{B}^{2}$

\section{Resumen}

Objetivo. Evaluar la capacidad biorremediadora de algunas especies de hongos filamentosos en suelos contaminados con petróleo crudo. Métodos. Se aislaron 138 cepas a partir de 90 cultivos primarios en muestras de suelos obtenidas en los municipios de Yondó (Antioquia), Acacías (Meta) y Tumaco (Nariño), se identificaron las especies por medio de claves taxonómicas y la amplificación por PCR de la región ITS ubicándose en siete géneros de hongos filamentosos. Del total de las especies se escogieron tres para el experimento que fueron: Neosartorya sp. Cepa A/N-1, Aspergillus sp. Cepa Y/As-3 y Rhizomucor sp. Cepa 1A/R-1; se realizó la micorremediación con la técnica de Landfarming modificado al diseñarse un microcosmos con $50 \mathrm{~g}$ de suelo contaminado con petróleo crudo ${ }^{\circ} \mathrm{API}$ de 21.6 a concentraciones de 20.000 ppm y $30.000 \mathrm{ppm}$ para cada una de las especies en un inóculo de 300 conidios $/ \mathrm{ml}$ en agua destilada, ajustado en cámara de Neubauer y las tres especies en consorcio en suelo contaminado con petróleo crudo ${ }^{\circ} \mathrm{API}$ de 21.6 a concentraciones de $40.000 \mathrm{ppm}, 60.000 \mathrm{ppm}, 80.000 \mathrm{ppm}$ y $100.000 \mathrm{ppm}$ con un inóculo de 300 conidios $/ \mathrm{ml}$. Se valoró el proceso por espectofotometría. Además se estableció las enzimas empleadas en la micorremediación y la citotoxicidad de las cepas empleadas. Resultado. La micorremediación realizada por las especies individuales fue en promedio entre 2 y 6 días y cuando se aplicaron las tres especies en consorcio se realizó en un promedio entre 6 y 10 días, la enzima empleada es peroxidasa y la citotoxicidad es negativa.

Palabras claves: Petróleo, contaminación ambiental, extremófilos, suelo, aplicación en el terreno.

\footnotetext{
1. Bacterióloga con énfasis en Microbiología Agrícola, Especialista en Gerencia de Riesgos Laborales, Seguridad y Salud en el Trabajo. Magister en Ciencias Ambientales. 


\begin{abstract}
Objective. Evaluate the bioremediation capacity of some species of filamentous fungi in soils contaminated with crude oil. Methods. 138 strains were isolated from 90 primary culture in soil samples obtained in the municipalities of Yondó (Antioquia), Acacías (Meta) and Tumaco (Narińo), species were identified by means of taxonomic keys and PCR amplification of the ITS region located in seven genera of filamentous fungi. Of the total of the species, three were chosen for the experiment, which were: Neosartorya sp. Cepa A/N-1, Aspergillus sp. Cepa Y/As-3 and Rhizomucor sp. Cepa 1A/R-1; Micoremediation was performed with the modified Landfarming technique when designing a microcosm with $50 \mathrm{~g}$ of soil contaminated with crude oil API 21.6 at concentrations of 20,000 ppm and $30,000 \mathrm{ppm}$ for each of the species in an inoculum of 300 conidia / $\mathrm{ml}$ in water distilled, adjusted in Neubauer chamber and the three species in consortium in soil contaminated with crude oil API 21.6 at concentrations of 40,000ppm, 60,000ppm, 80,000ppm and 100,000ppm with an inoculum of 300 conidia / $\mathrm{ml}$. The process was evaluated by spectrophotometry. In addition, the enzymes used in the micoremediation and cytotoxicity of the strains used were established. Result. The micoremediation performed by the individual species was on average between 2 and 6 days and when the three species were applied in a consortium it was carried out on average between 6 and 10 days, the enzyme used is peroxidase and the cytotoxicity is negative.
\end{abstract}

Keywords: Oil, environmental pollution, extremophiles, soil, application in the field.

\title{
Introducción
}

Los suelos contaminados por derrame de petróleo crudo son un problema de gran trascendencia mundial. Particularmente, su impacto es negativo Colombia, por su potencial agrícola y forestal $(1,2$, 3, 4, 5, 6). La transformación en los últimos años hacia la producción petrolera, bajo el amparo de la "locomotora minero energética" emprendida por los últimos gobiernos nacionales, regionales y locales generaron que en la actualidad la industria petrolera tenga títulos para la producción o extracción de petróleo crudo para 26 millones de hectáreas, equivalente al $21 \%$ del total del territorio nacional $(7,8)$. Las redes de transporte de este mineral, como son oleoductos y poliductos, poseen una longitud calculada en 5.467 kilómetros, cruzan el territorio colombiano de oriente a occidente hacia los principales puertos marítimos que a su vez son los lugares de extracción del crudo del país (9). Estas redes de transporte atraviesan diversos e invaluables ecosistemas en los cuales, ya sea por accidente o por motivaciones delictivas son destruidos, ocasionando un derrame de petróleo crudo y generando contaminación de suelos, agua y aire (4).
Benavides y colaboradores (10) estimaron que entre 1986 y 1998, según datos oficiales publicados en este campo, los atentados a oleoductos en Colombia generaron el derrame de dos millones de barriles de petróleo, los cuales afectaron cuerpos hídricos y suelos de uso tanto agro-industrial como forestal. Otros investigadores $(7,11)$ aseguraron que se ha derramado 7.6 veces más que el petróleo que se derramó en el desastre del buque Exxon Valdés entre Alaska y Canadá el 24 de Marzo de 1989.

Según Wang (12), las características inherentes del petróleo crudo corresponden a una mezcla de varias sustancias de origen orgánico con variado tamaño y estructura, con la capacidad de afectar grandes extensiones de suelo y cuerpos hídricos tanto superficiales como subterráneos, los cuales en su mayoría pueden ser recuperados totalmente por la combinación de tecnologías desarrolladas para este fin. En un derrame de petróleo crudo en el suelo se afecta su estructura físico-química y biológica, como por ejemplo la relación carbono, nitrógeno y fósforo. Este último elemento es considerado escaso para 
los suelos colombianos, lo cual genera un impacto directo en los procesos fotosintéticos en plantas y altera la biota circundante $(13,14)$. Además hay afectación severa sobre la germinación de semillas ya que inhiben dicho proceso, altera el crecimiento vegetal y produce necrosis foliar $(15,16)$. Así, se reducen drásticamente las poblaciones macro y microbianas nativas, lo cual es perjudicial y trascendental para Colombia, pues al ser un país mega diverso, la ocurrencia de un derrame de petróleo crudo impacta su potencial biológico $(2,3)$.

Dentro de las pocas especies que sobreviven a la contaminación con petróleo crudo, hacen parte los hongos filamentosos. Estos se caracterizan por ser aerobios, de amplia distribución geográfica, extremófilos (es decir, capaces de reproducirse en niveles de $\mathrm{pH}$ que oscilan entre 3 hasta 12), resistentes a temperaturas entre $2^{\circ} \mathrm{C}$ y $60^{\circ} \mathrm{C}$; en su mayoría son simbióticos con las demás especies microbianas presentes en los suelos, y los hidrocarburolíticos poseen un mecanismo de supervivencia adaptativo para utilizar el carbono desde el petróleo crudo como fuente energética, lo cual permite utilizarles como organismos promisorios en procesos de biorremediación $(12,17,18)$.

Al utilizar una técnica de biorremediación in situ, posterior a un derrame de petróleo crudo sobre suelo, los hongos filamentosos hidrocarburolíticos son útiles ya que al no generar metano como residuo final del proceso, son organismos que no contribuyen al efecto invernadero y al cambio climático (19). Una de las causas de estos problemas ambientales es la acumulación de gases tóxicos en el ambiente como son el anhídrido carbónico, óxido nitroso, ozono, amonio y metano; este último tiene una vida media en la atmósfera de 12 ańos y contribuye 25 veces más al calentamiento global que el anhídrido carbónico. El residuo final al utilizar hongos filamentosos hidrocarburolíticos son biomasa, agua y $\mathrm{CO}(12,20,21,22,23,24,25)$.

El mecanismo de acción de los hongos filamentosos está basado en la aerobiosis, se destaca por desencadenar un proceso totalmente oxidativo del sustrato para obtener su energía metabólica y el desarrollo de su cadena respiratoria, en donde el oxígeno actúa como aceptor final de electrones (26). En la presencia de oxígeno molecular es catalizado por enzimas presentes en el citoplasma celular, denominadas oxigenasas; las cuales pueden ser de tipo monooxigenasa (esto es, que incorporan un solo átomo al proceso y reducen el otro para generar agua) o dioxigenasa (es decir, las que adhieren ambos átomos de oxígeno al proceso) (27, 28, 29, 30,31). Cabe resaltar que la actividad enzimática de los hongos filamentosos se presenta a partir de tres mecanismos enzimáticos, lignina oxidasas, lignina per oxidasas y lignina hidrolasas $(28,32,33,34$, $35,36,37)$.

En el desarrollo de este proyecto se aislaron hongos filamentosos presentes en suelos contaminados por derrame de petróleo crudo en tres lugares correspondientes a tres regiones de Colombia, a saber, Antioquia, Meta y Nariño, con características ambientales diferentes. Se evaluó su capacidad biorremediadora in vitro sobre este sustrato en suelo contaminado con este, artificialmente por medio de la técnica landfarming modificada a diferentes concentraciones y se determinó el mecanismo de acción por el cual dichas especies degradan el contaminante mencionado.

\section{Metodología}

Muestreo del suelo: se recolectaron muestras de suelo en tres lugares geográficos diferentes en Colombia (figura 1), en los cuales hubo derrames de petróleo crudo desde oleoductos, con la finalidad de aislar especies de hongos filamentosos. 
Figura 1. Localización de los sitios de muestreo.

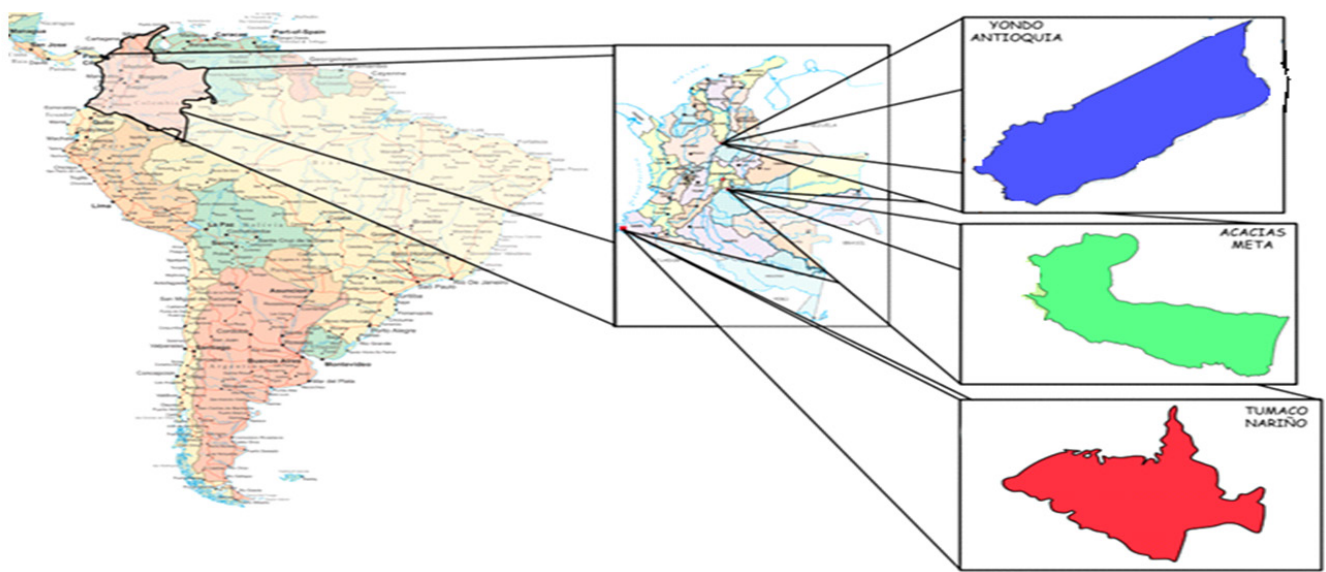

Fuente. (Tomado de: http: //www.zonu.com/fullsize2/2009-11-18-11141/Mapa-Politico-de-America-del-Sur.html, http: // histórico.presidencia.gov.co/asiescolombia/mapacol.htm.http://www.tumaconarino.gov.co/mapas_municipio.shtml?apc=bcxx-1-\&x=1364266), modificada y diseñada por Daniela de Los Ángeles Cáceres Bedoya.

En el cuadro 1 se indican las características de los si- no en el municipio de Yondó (Antioquia). En la retios de muestreo y datos de su localización. La toma colección de las muestras de suelo en el municipio de muestras de suelo se realizó por medio de la ela- de Acacías (Meta) y Tumaco (Nariño) se utilizó cuboración de cajuelas de $20 \mathrm{~cm}$ X $20 \mathrm{~cm} \mathrm{X} 10 \mathrm{~cm}$ de charón de draga manual debido a que el suelo conlas cuales se extrajeron $500 \mathrm{~g}$ de muestra con barre- taminado estaba cerca a los cuerpos de agua (41).

Cuadro 1. Características de los lugares donde se tomaron las muestras de suelo contaminadas con hidrocarburos.

\begin{tabular}{|c|c|c|}
\hline YONDÓ (ANTIOQUÍA) & ACACIAS (META) & TUMACO (NARIÑO) \\
\hline $\begin{array}{l}\text { Zona rural del municipio, altitud: } 75 \\
\text { m.s.n.m. Temperatura promedio } 30^{\circ} \mathrm{C} \text {, } \\
\text { humedad relativa } 85 \% \text { y precipitación } \\
2.150 \mathrm{~mm} \text { (promedios multianuales) } \\
\text { (IDEAM 2015). }\end{array}$ & $\begin{array}{l}\text { Zona rural del municipio, altitud es de } \\
498 \text { m.s.n.m. Temperatura promedio } \\
25^{\circ} \mathrm{C} \text {, humedad relativa } 75 \% \text {, } \\
\text { precipitación } 3.000 \mathrm{~mm} \text { (promedios } \\
\text { multianuales) (IDEAM 2015). }\end{array}$ & $\begin{array}{l}\text { Zona rural del municipio, altitud es } \\
\text { de } 1 \text { m.s.n.m. Temperatura promedio } \\
28^{\circ} \mathrm{C} \text {, humedad relativa } 83.86 \% \text { y } \\
\text { precipitación } 2.531 \mathrm{~mm} \text { (promedios } \\
\text { multianuales) (IDEAM 2015). }\end{array}$ \\
\hline $\begin{array}{l}\text { En la zona, posterior al derrame de } \\
\text { hidrocarburo, no crece vegetación } \\
\text { pese a no observarse el contaminante, } \\
\text { fue un derrame ocasionado por un } \\
\text { atentado. Las coordenadas son: } 6^{\circ} 59^{\prime} \\
31,0^{\prime} \mathrm{N}, 73^{\circ} 56^{\prime} 50.3^{\prime} \text { W y } 73^{\circ} 56^{\prime} \\
54.0^{\prime} \mathrm{W} \text {. }\end{array}$ & $\begin{array}{l}\text { Derrames ocasionados por descuidos } \\
\text { consecutivos en la operación de } \\
\text { extracción y que afectó varios cuerpos } \\
\text { de agua y suelos de las laderas. Las } \\
\text { Coordenadas son: } 3^{\circ} 49^{\prime} 35.9^{\prime \prime} \mathrm{N} \text { y } 03^{\circ} \\
57^{\prime} 2009^{\prime} \mathrm{N} \text { y } 73^{\circ} 37^{\prime} 51^{\prime \prime} \mathrm{W} \text { y } 73^{\circ} \\
43^{\prime} 40.0^{\prime \prime} \mathrm{W} \text {. }\end{array}$ & $\begin{array}{l}\text { En las laderas del río Inda, municipio } \\
\text { de Tumaco, departamento de Nariño. } \\
\text { La zona se caracteriza por derrames } \\
\text { ocasionados por atentados terroristas } \\
\text { al oleoducto en cercanías al puerto en } \\
\text { el Pacífico. Las coordenadas son } 1^{\circ} 26^{\prime} \\
11.0^{\prime} \text { y N y } 1^{\circ} 26^{\prime} 14.0^{\prime} \mathrm{N} \text { y } 78^{\circ} 31^{\prime} \\
26.5^{\prime} \text { W y } 78^{\circ} 31^{\prime} 28.0^{\prime} \mathrm{W} \text {. }\end{array}$ \\
\hline $\begin{array}{l}\text { Los suelos son ácidos hasta neutros } \\
\text { y moderadamente alcalinos, con } \\
\text { alto contenido orgánico, muchos de } \\
\text { ellos de origen volcánico y con altos } \\
\text { contenidos de alófono, profundos } \\
\text { y de buena textura, algunos francos } \\
\text { arcillosos de topografía plana tienden a } \\
\text { ser inundables. (Pallarez 2015) }\end{array}$ & $\begin{array}{l}\text { Los suelos son de baja fertilidad y de } \\
\text { alta resistencia a la alteración, son ricos } \\
\text { en hierro y aluminio y se caracterizan } \\
\text { por bajos contenidos de carbono } \\
\text { orgánico y minerales primarios. } \\
\text { (Pallarez 2015). }\end{array}$ & $\begin{array}{l}\text { Son suelos que se caracterizan por ser } \\
\text { fértiles y de } \mathrm{pH} \text { entre } 6.0 \text { hasta } 6.9 \\
\text { (Pallarez 2015). }\end{array}$ \\
\hline
\end{tabular}

Fuente. Elaboración propia. 
Se tomaron 10 muestras de suelo por sitio de muestreo en las áreas mencionadas, con el propósito de homogenizarlas (42). Además, se tomó una muestra de suelo control correspondiente a cada sitio muestreado, en lugares sin rastro o evidencia de afectación por contaminación con petróleo crudo, para realizar la comparación respectiva. El muestreo fue de tipo preferencial en el sentido que se localizaron las zonas de afectación por petróleo crudo para tomar las muestras y de allí fue recolectado el suelo, igualmente se hizo lo mismo para las muestras control. Se seleccionó este tipo de muestreo por las complicaciones existentes, de accesibilidad y seguridad, para acceder a los puntos de muestreo con suelos contaminados con petróleo crudo.

Condiciones de transporte de las muestras: las muestras fueron colocadas en bolsas de papel y de plástico previamente esterilizadas; se tomaron en total 33 muestras, las cuales fueron depositadas en una nevera de icopor con hielo con el fin de preservarlas en una temperatura de $4^{\circ} \mathrm{C}$ y transportadas inmediatamente a los laboratorios de la Universidad de Ciencias Aplicadas y Ambientales para su procesamiento basado en la norma (43).

Siembra primaria de las muestras de suelo: se sembraron las muestras de suelo contaminadas con petróleo crudo, recolectadas previamente en cada uno de los lugares donde se obtuvieron las muestras de suelo originalmente, por triplicado, para un total de noventa y nueve cajas de Petri, posterior a hacerse una dilución en $5 \mathrm{ml}$ de solución salina al $0.9 \%$, con $1 \mathrm{~g}$ de la muestra de suelo, directamente sobre el medio PDA + cloranfenicol por un periodo entre 2 a 7 días a $25^{\circ} \mathrm{C}$. El protocolo fue modificado según la metodología (43).

Aislamiento e identificación de hongos filamentosos de las muestras de suelo: se seleccionaron cepas de hongos filamentosos que crecieron en el cultivo primario por zona de muestreo y cada una de ellas fue sembrada en una caja de Petri con el medio PDA + cloranfenicol, se incubó entre 2 y
7 días a $25^{\circ} \mathrm{C}$, para su posterior identificación; al final del proceso, se seleccionaron los hongos con crecimiento en común en los tres suelos muestreados y se identificaron a partir de las características macroscópicas y microscópicas utilizando claves taxonómicas $(45,46,47)$.

Cuantificación del petróleo crudo en los suelos muestreados: después de realizar la extracción y/o fraccionamiento del petróleo crudo contenido en una muestra de suelo, estos se pueden cuantificar por varios métodos, en este caso se realizó la cuantificación por método gravimétrico (48).

Análisis físico-químico del suelo muestreado inicialmente y contaminado con petróleo crudo y las muestras control: las pruebas básicas que se realizaron a las muestras de suelo contaminadas con petróleo crudo fueron: $\mathrm{pH}$, amonio, conductividad eléctrica, fosfatos, nitratos y nitritos basado en él $(48,49)$.

Caracterización del petróleo crudo: se realizó una caracterización del petróleo crudo por medio de las pruebas BSW y el ${ }^{\circ} \mathrm{API}$, para saber qué tipo de crudo se estaba empleando en la evaluación de la capacidad biorremediadora in vitro, teniendo en cuenta que el origen de éste es de un pozo petrolero de Puerto Gaitán (Meta) según lo establecido $(50,51)$.

Método de agitación por centrifugación para la determinación de la capacidad biorremediadora de los hongos filamentosos: este método cuantitativo para la extracción de petróleo crudo de sustratos como el suelo, es utilizado por su economía, rapidez y sencillez en la técnica. En cuanto a la velocidad de agitación y volúmenes de solventes por utilizar, esta se basa en los métodos descritos en $(48,52,53,54,55,56)$.

Método de evaluación in vitro de la capacidad biorremediadora de tres cepas de hongos filamentosos: el análisis de las muestras de suelo contaminadas con petróleo crudo se basó en di- 
señar un microcosmos, en el cual a $50 \mathrm{~g}$ de suelo contaminado de manera artificial con diferentes concentraciones de petróleo crudo pesado (20.000 ppm, 30.000 ppm, 40.000 ppm, 60.000 ppm, 80.000 ppm, 100.000 ppm) se agregó $3 \mathrm{ml}$ de caldo nutricional/día, se aplicó aire continuo a cada tratamiento y se mantuvo la temperatura constante a $32^{\circ} \mathrm{C}$, generando un ambiente artificial tratando de imitar las condiciones originales de los suelos. A estos montajes se adicionó conidios de hongos filamentosos por separado así como en consorcio. Cabe destacar que a partir de la caracterización morfológica y la correlación con las referencias bibliográficas se determinaron la capacidad biorremediadora de los hongos aislados en otros estudios, se escogieron tres cepas de las aisladas inicialmente, teniendo en cuenta el tiempo de crecimiento, el cual estuvo en el rango de 24-48 horas. Este inóculo se ajustó en una proporción de 300 conidios $/ \mathrm{ml}$ en agua destilada, con ayuda de la cámara de Neubauer y como control positivo se utilizó el hongo Penicillium janthinellum. Posterior a este procedimiento se analizó periódicamente la capacidad biorremediadora con un espectofotómetro UV-VIS 6405, JENWAY modelo 6405, hasta obtener cero de absorbancia $(48,57,58,59)$.

\section{Determinación preliminar in vitro de las enzi-} mas utilizadas por los hongos filamentosos en el proceso de biorremediación: como parte del proceso, se evaluó cualitativamente el mecanismo de acción desarrollado por el hongo filamentoso in vitro para realizar la actividad biorremediadora del petróleo crudo mediante peroxidasa y oxidasa $(21,36,37,60)$.

Determinación de la citotoxicidad de los hongos seleccionados en la biorremediación: se estableció la capacidad de citotoxicidad en plantas de Allium fistulosum, las cuales fueron inoculadas con las cepas seleccionadas para el proceso de biorremediación. Para este experimento se colocaron en un medio líquido con macro y micro nutrientes: CaNO3, 5g/L; KNO3, 5g/L; MgSO4, 2g/L;
KH2PO4 1g/L quelato de Fe, 1g/L; agua destilada, $1 \mathrm{~L}$, cloranfenicol $0.5 \mathrm{~g} / \mathrm{L}$. Se dejaron durante 14 días en el medio líquido con los nutrientes y las colonias de hongos utilizadas en el proceso de biorremediación.

Análisis de datos: se realizó por medio de análisis de varianza a partir de los resultados obtenidos de la cuantificación de la efectividad de los hongos filamentosos utilizados y las concentraciones de petróleo crudo a los cuales se sometieron los géneros micológicos, su capacidad biorremediadora en consorcio con relación al tiempo a partir de un ANOVA y la prueba de comparación usada fue la HSD (Diferencia Honesta Significativa) o prueba de Tukey, respectivamente. Se realizaron dos experimentos distintos, el primero se realizó bajo una estructura aleatoria con arreglo factorial del tipo 3 x 2 (Género x Concentración de petróleo), mientras que para el experimento 2 fue del tipo Diseño completamente al azar - DCA con 4 tratamientos, los cuales se describen a continuación:

Aplicación de las tres cepas (identificadas hasta género) de hongos a nivel individual: se realizó un diseño aleatorizado con dos (2) factores, el hongo filamentoso (que fue identificado a nivel de género) y la concentración del petróleo crudo. Estos factores tienen 3 y 2 niveles respectivamente, que son, por una parte, Neosartorya sp. Cepa A/N-1, Aspergillus sp. Cepa Y/As-3 y Rhizomucor $\boldsymbol{s p}$. Cepa 1A/R-1; y por otra, las concentraciones de $20.000 \mathrm{ppm}$ y $30.000 \mathrm{ppm}$, para evaluar nuevamente el tiempo en el cual los hongos desarrollaron el proceso de biorremediación en suelo a partir del nivel de absorbancia.

Aplicación de los cepas (identificadas a nivel de género) de hongos en consorcio: se utilizaron los hongos Neosartorya sp. Cepa A/N-1, Aspergillus sp. Cepa Y/As-3 y Rhizomucor sp. Cepa 1A/R-1. En consorcio a 300 conidios, 100 de cada género aislado en diferentes concentraciones de petróleo crudo $(40.000$ ppm, 60.000 ppm, 80.000 ppm y $100.000 \mathrm{ppm})$, por triplicado, para evaluar el 
tiempo en el cual los hongos filamentosos generaron el proceso de biorremediación en suelo, lo cual se midió a partir del nivel de absorbancia.

Cada uno de los 125 resultados en el proyecto, se anexa a una tabla de tabulación de los datos utilizando el software MSExcel y el procesamiento de los mismos, con el lenguaje de programación $(61,62)$. A través del diseño factorial múltiple, en este esquema se tuvo en cuenta las cuatro variables independientes que son: la concentración del petróleo crudo diluida en el sustrato, la cantidad de conidios de hongos filamentoso (identificados hasta nivel de género), el tiempo como variable dependiente y la capacidad biorremediadora.

\section{Resultados}

En la Tabla 1 se encuentran los resultados de los contenidos de hidrocarburos totales presentes en las muestras utilizadas para el proyecto, los cuales se obtuvieron por el método gravimétrico, y se corroboraron en un laboratorio certificado por el IDEAM (CHEBILAB). Además se realizaron otras pruebas como: $\mathrm{pH}$, conductividad eléctrica, amonios, nitratos, nitritos y fosfatos.

Tabla 1. Resultado del análisis físico-químico de las muestras de suelo. Los análisis de Hidrocarburos totales se realizaron en el laboratorio Chemilab, acreditado por el IDEAM.

\begin{tabular}{|c|c|c|c|c|c|c|}
\hline $\begin{array}{l}\text { Prueba } \\
\text { realizada }\end{array}$ & $\begin{array}{l}\text { Muestra } \\
\text { de Yondó } \\
\text { Antioquia }\end{array}$ & $\begin{array}{l}\text { Muestra } \\
\text { control } \\
\text { de Yondó } \\
\text { Antioquia }\end{array}$ & $\begin{array}{c}\text { Muestra de } \\
\text { Acacias Meta }\end{array}$ & $\begin{array}{l}\text { Muestra } \\
\text { control de } \\
\text { Acacias Meta }\end{array}$ & $\begin{array}{l}\text { Muestra } \\
\text { de Tumaco } \\
\text { Nariño. }\end{array}$ & $\begin{array}{l}\text { Muestra } \\
\text { control de } \\
\text { Tumaco } \\
\text { Nariño. }\end{array}$ \\
\hline $\begin{array}{l}\text { Hidrocarburos } \\
\text { totales }(\mathrm{TPH}) \\
\text { en muestras de } \\
\text { suelo }\end{array}$ & $0.797 \%$ & $0.0002 \%$ & $0.931 \%$ & $0.003 \%$ & $1.2 \%$ & $0.003 \%$ \\
\hline $\mathrm{pH}$ & 4.77 (F A) & 5.31 & $5.64(\mathrm{M} \mathrm{A})$ & 7.8 & $6.03(\mathrm{M} \mathrm{A})$ & 8.0 \\
\hline $\begin{array}{l}\text { Conductividad } \\
\text { eléctrica } \\
(\mathrm{mmhos} / \mathrm{cm})\end{array}$ & 40 (EX S) & 9 & 135 (EX S) & 28 & 5 (MS) & 305 \\
\hline $\begin{array}{l}\text { Amonio mg/ } \\
\mathrm{Kg}\end{array}$ & 0.02537 (EXP) & 3.2 & 0.04971 (EXP) & 4.8 & $0.01572(\mathrm{EXP})$ & 5.3 \\
\hline $\begin{array}{l}\text { Nitratos mg/ } \\
\mathrm{Kg}\end{array}$ & $0.00012(\mathrm{EXP})$ & 13.024 & $0.00019(\mathrm{EXP})$ & 10.224 & $0.00013(\mathrm{EXP})$ & 3.28 \\
\hline Nitritos $\mathrm{mg} / \mathrm{Kg}$ & 0.23935 (EXP) & 0.10 & $0.42275(\mathrm{EXP})$ & 0.01 & 0.32642 (EXP) & 0.03 \\
\hline $\begin{array}{l}\text { Fosfatos mg/ } \\
\mathrm{Kg} \text {. }\end{array}$ & 0.01275 (B) & 0.10 & $0.09441(\mathrm{~B})$ & 0.2 & $0.04661(\mathrm{~B})$ & 0.1 \\
\hline \multicolumn{7}{|c|}{$\begin{array}{l}\text { pH: FA: Fuertemente ácido. MA: Moderadamente ácido. } \\
\text { Conductividad eléctrica: EX S: Extremadamente salina. MS: Moderadamente salina. } \\
\text { Amonio, Nitratos y Nitritos: EXP: Extremadamente pobre. } \\
\text { Fosfatos: Bajos (48). }\end{array}$} \\
\hline
\end{tabular}

Fuente. Elaboración propia. 
Identificación de hongos filamentosos obtenidos en las muestras de suelos contaminados con petróleo crudo: se aislaron 138 cepas a partir de 90 cultivos primarios de las muestras de suelo contaminado con petróleo crudo obtenidos en los municipios de Yondó (Antioquia), Acacías (Meta) y Tumaco (Nariño), teniendo en cuenta sus características macroscópicas y microscópicas, confirmadas con las claves taxonómicas de $(45,46,47)$; así como la amplificación por PCR de la región ITS (Transcripción interna espaciador) ubicándose la totalidad de las cepas en siete géneros de hongos filamentosos. Como control del proceso de identificación de los hongos presentes en las muestras de suelo contaminado con petróleo crudo se tomaron muestras de suelos ubicados en cada uno de los lugares muestreados, es decir Yondó (Antioquia),
Acacías (Meta) y Tumaco (Narińo) para un total de tres muestras, las cuales fueron obtenidas evidenciando por información de la comunidad aledańa y por análisis en el laboratorio que no estuvieran contaminadas con petróleo crudo, así como el análisis físico-químico de suelo. Este procedimiento se realizó con el objetivo de confirmar la presencia de los hongos filamentosos reportados en los suelos con petróleo crudo y descartar que las muestras se hubiesen contaminado en cualquiera de los procedimientos previos a la identificación de estas especies. Los resultados de la identificación de cada una de las muestras contaminadas con petróleo crudo se presentan en la Tabla 2.

Tabla 2. Cepas obtenidas en muestras de suelo contaminado con petróleo crudo obtenidas en los municipios de Yondó (Antioquia), Acacias (Meta) y Tumaco (Nariño) identificadas por claves taxonómicas o por PCR.

\begin{tabular}{|c|c|c|c|c|c|}
\hline $\begin{array}{l}\text { LUGARES DE } \\
\text { MUESTREOY } \\
\text { CANTIDAD TOTAL } \\
\text { DE CEPAS }\end{array}$ & $\begin{array}{c}\text { \# CEPAS } \\
\text { IDENTIFICADAS }\end{array}$ & $\begin{array}{l}\text { CARACTERISTICAS } \\
\text { MACROSCÓPICAS }\end{array}$ & $\begin{array}{l}\text { CARACTERISTICAS } \\
\text { MICROSCÓPICAS }\end{array}$ & $\begin{array}{c}\text { IDENTIFICACIÓN } \\
\text { TAXONÓMICA } \\
\text { Claves taxonómicas } \\
\text { de (Alexopoulos } \\
\text { 1996, Barnett y } \\
\text { Hunter 1976, Arenas, } \\
2003\end{array}$ & $\begin{array}{l}\text { IDENTIFICACIÓN } \\
\text { POR \% DE } \\
\text { SIMILITUD. } \\
\text { Amplificación de la } \\
\text { región ITS con un } \\
\text { 100\% de similitud } \\
\text { para el género }\end{array}$ \\
\hline \multirow{4}{*}{$\begin{array}{l}\text { * Yondó (ANT) } 74 \\
\text { cepas en total. } \\
{ }^{*} \text { Acacias (Meta) } 36 \\
\text { cepas en total. } \\
\text { * Tumaco } \\
\text { (Nariño) } 28 \text { cepas en } \\
\text { total. }\end{array}$} & $\begin{array}{l}\text { *40 Cepas Y/As } \\
\text { CA }=1-40 \\
* 10 \text { cepas } \mathrm{A} / \mathrm{As} \\
\mathrm{CA}=1-10 \\
* 8 \text { cepas } \mathrm{T} / \mathrm{As} \mathrm{CA}= \\
1-8 .\end{array}$ & $\begin{array}{l}\text { Colonia de color } \\
\text { verde oliva, aspecto } \\
\text { pulverulento. }\end{array}$ & $\begin{array}{l}\text { Hifas hialinas, } \\
\text { presencia de vesículas } \\
\text { y fiálides }\end{array}$ & Aspergillus sp & \\
\hline & $\begin{array}{l}\text { *2 cepas } \mathrm{Y} / \mathrm{R} \mathrm{CA}=1 \\
\text { y } 2 \\
* 3 \text { cepas } \mathrm{A} / \mathrm{R} \\
\mathrm{CA}=1-3 \\
* 2 \text { cepas } \mathrm{T} / \mathrm{R} \mathrm{CA}=1 \\
\text { y } 2 \text {. }\end{array}$ & $\begin{array}{l}\text { Colonia de color rojo, } \\
\text { de borde irregular y } \\
\text { aspecto cremoso }\end{array}$ & $\begin{array}{l}\text { Poseen esporangios de } \\
\text { color marrón claro a } \\
\text { marrón ramificados } \\
\text { en tonos hialinos y } \\
\text { marrones }\end{array}$ & Rhizomucor sp & \\
\hline & $\begin{array}{l}* 2 \text { cepas } \mathrm{Y} / \mathrm{M} \mathrm{CA}=1 \\
\text { y } 2 \\
* 2 \text { cepas } \mathrm{A} / \mathrm{M} \mathrm{CA}=1 \\
\text { y } 2 \\
\text { * } 2 \text { cepas } \mathrm{T} / \mathrm{M} \mathrm{CA}=1 \\
\text { y } 2 .\end{array}$ & $\begin{array}{l}\text { Colonia de aspecto } \\
\text { algodonoso, color } \\
\text { blanco. }\end{array}$ & $\begin{array}{l}\text { Es un hongo } \\
\text { demateaceo el cual } \\
\text { posee filamentos } \\
\text { tubulares blancos y } \\
\text { esporangios negros } \\
\text { esféricos }\end{array}$ & Mucor sp. & \\
\hline & $\begin{array}{l}\text { * } 5 \text { cepas } \mathrm{Y} / \mathrm{Abs} \mathrm{CA}= \\
1-5 \\
* 7 \text { cepas } \mathrm{A} / \mathrm{Abs} \\
\mathrm{CA}=1-7 \\
* 4 \text { cepas T/Abs } \mathrm{CA}= \\
1-4\end{array}$ & $\begin{array}{l}\text { Colonias de color } \\
\text { entre blanco a beige, } \\
\text { aspecto algodonoso y } \\
\text { el revés es del mismo } \\
\text { color. }\end{array}$ & $\begin{array}{l}\text { Hifas hialinas, gruesas, } \\
\text { septadas, de pared } \\
\text { delgada. Esporangios } \\
\text { con esporangiosporas. } \\
\text { Esporangióforos } \\
\text { ramificados, } \\
\text { desarrollados a partir } \\
\text { de los estolones a } \\
\text { cierta distancia de los } \\
\text { rizoides. }\end{array}$ & Absidia sp. & \\
\hline
\end{tabular}




\begin{tabular}{|c|c|c|c|c|c|}
\hline $\begin{array}{c}\text { LUGARES DE } \\
\text { MUESTREO Y } \\
\text { CANTIDAD TOTAL } \\
\text { DE CEPAS }\end{array}$ & $\begin{array}{c}\text { \# CEPAS } \\
\text { IDENTIFICADAS }\end{array}$ & $\begin{array}{l}\text { CARACTERISTICAS } \\
\text { MACROSCÓPICAS }\end{array}$ & $\begin{array}{l}\text { CARACTERISTICAS } \\
\text { MICROSCÓPICAS }\end{array}$ & $\begin{array}{l}\text { IDENTIFICACIÓN } \\
\text { TAXONÓMICA } \\
\text { Claves taxonómicas } \\
\text { de (Alexopoulos } \\
\text { 1996, Barnett y } \\
\text { Hunter 1976, Arenas, } \\
2003\end{array}$ & $\begin{array}{l}\text { IDENTIFICACIÓN } \\
\text { POR \% DE } \\
\text { SIMILITUD. } \\
\text { Amplificación de la } \\
\text { región ITS con un } \\
\text { 100\% de similitud } \\
\text { para el género }\end{array}$ \\
\hline \multirow{3}{*}{$\begin{array}{l}\text { * Yondó (ANT) } 74 \\
\text { cepas en total. } \\
\text { * Acacias (Meta) } 36 \\
\text { cepas en total. } \\
\text { * Tumaco } \\
\text { (Nariño) } 28 \text { cepas en } \\
\text { total. }\end{array}$} & $\begin{array}{l}* 3 \text { cepas Y/N } \\
\mathrm{CA}=1-3 \\
* 1 \text { cepa } \mathrm{A} / \mathrm{N} \\
* 2 \text { cepas } \mathrm{T} / \mathrm{N} \mathrm{CA}= \\
1 \text { y } 2 .\end{array}$ & $\begin{array}{l}\text { Colonias de color } \\
\text { gris azul, con borde } \\
\text { regulares, aspecto } \\
\text { puntiforme y el revés } \\
\text { es de color rosado. }\end{array}$ & $\begin{array}{l}\text { Tiene hifas aéreas, } \\
\text { ascosporas con } \\
\text { dos crestas en sus } \\
\text { extremos, conspicuas } \\
\text { y con la superficie } \\
\text { convexa micro } \\
\text { tuberculada. }\end{array}$ & & Neosartorya sp \\
\hline & $\begin{array}{l}\text { * } 2 \text { cepas marcadas } \\
\text { con las letras } \mathrm{Y} / \mathrm{Pho} \\
\mathrm{CA}=1 \text { y } 2 \\
\text { *1 cepa } \mathrm{A} / \mathrm{Pho} \\
\text { *2 cepas } \mathrm{T} / \mathrm{Pho} \mathrm{CA}=1 \\
\text { y } 2\end{array}$ & $\begin{array}{l}\text { Colonias de color } \\
\text { marrón y aspecto } \\
\text { polvoriento. }\end{array}$ & $\begin{array}{l}\text { Presenta esporas } \\
\text { hialinas unicelulares }\end{array}$ & & Phoma sp \\
\hline & $\begin{array}{l}* 20 \text { cepas } \mathrm{Y} / \mathrm{P} \mathrm{CA}= \\
1-20 \\
* 10 \text { cepas } \mathrm{A} / \mathrm{P} \mathrm{CA}= \\
1-10 \\
* 8 \text { cepas } \mathrm{T} / \mathrm{P} \\
\mathrm{CA}=1-8\end{array}$ & $\begin{array}{l}\text { Colonias con bordes } \\
\text { regulares superpuestas } \\
\text { por crecimiento } \\
\text { algodonoso de color } \\
\text { blanco y en el envés } \\
\text { el crecimiento es de } \\
\text { color amarillo oscuro a } \\
\text { naranjado }\end{array}$ & $\begin{array}{l}\text { Poseen hifas septadas } \\
\text { hialinas, con } \\
\text { conidióforos simples o } \\
\text { ramificadas, métulas, } \\
\text { fálides y conidias }\end{array}$ & & Penicillium sp \\
\hline
\end{tabular}

Fuente. Elaboración propia.

Caracterización del petróleo crudo utilizado en la biorremediación: la prueba BSW dio como resultado $0.924 \mathrm{~g} / \mathrm{cm} 3=21.6^{\circ} \mathrm{API}$; según la clasificación internacional de hidrocarburos que es un petróleo crudo pesado (63); lo cual indica que es un componente cuya estructura química se caracteriza por tener cadenas dentro de su composición como son las resinas en un $30 \%$, asfáltenos un $5.8 \%$ y aromáticos saturados en un porcentaje aproximado de 64\% (64). En su estructura química el petróleo crudo presenta tanto en las resinas, los asfáltenos y los aromáticos saturados un alto peso molecular, poseen anillos bencénicos ligados con cadenas alquílicas y ciclo-alcanos los cuales se fusionan entre sí a partir de enlaces sencillos, dobles o triples. También contiene metales como el vanadio, níquel y el hierro y elementos como el azufre, el nitrógeno y el oxígeno los cuales componen los heteroátomos, estructuras que son características en estas sustancias $(65,66,67)$.
Evaluación de la capacidad biorremediadora de tres géneros de hongos filamentosos a diferentes concentraciones de petróleo crudo pesado: se realizó una medición por espectofotometría de la capacidad biorremediadora de los hongos Neosartorya sp. Cepa A/N-1, Aspergillus sp. Cepa Y/As-3 y Rhizomucor sp. Cepa 1A/R-1, individualmente en suelo contaminado con petróleo crudo pesado a concentraciones de $20.000 \mathrm{ppm}$ y $30.000 \mathrm{ppm}$ y utilizando las tres cepas en consorcio en suelo contaminado con petróleo crudo pesado a concentraciones de $40.000 \mathrm{ppm}, 60.000 \mathrm{ppm}, 80.000 \mathrm{ppm}$ y $100.000 \mathrm{ppm}$ obteniendo como resultado 125 datos de absorbancia, los cuales se observan en las cinéticas correspondientes a las Figuras 2 y 3 , respectivamente. 
Figura 2. Cinética de los géneros de los hongos Neosartorya sp. Cepa A/N-1, Aspergillus sp. Cepa Y/As-3 y Rhizomucor sp. Cepa 1A/R-1. Sobre suelo contaminado con petróleo crudo.

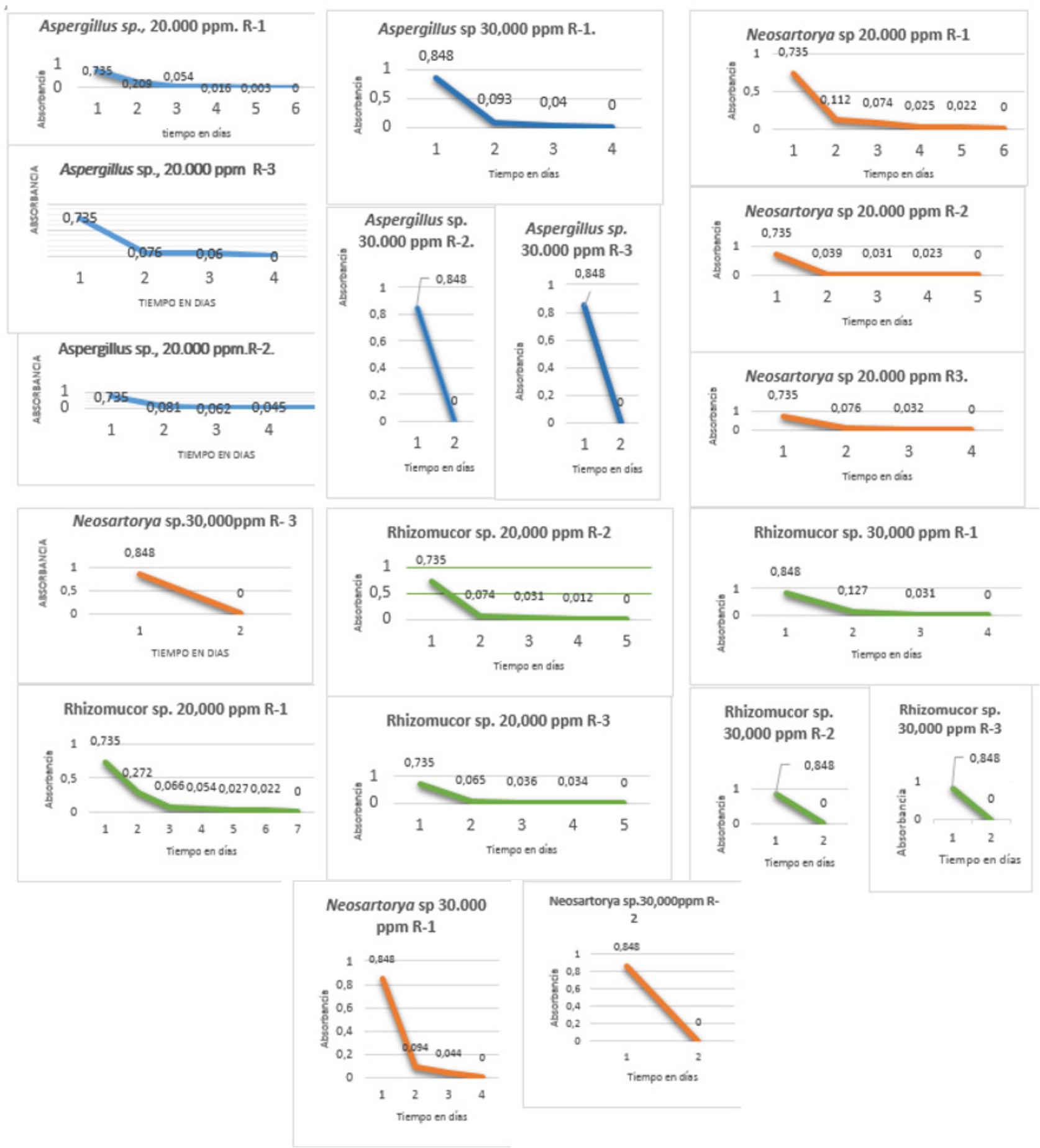

Fuente. Elaboración propia. 
Figura 3. Cinética del consorcio: Neosartorya sp. Cepa A/N-1, Aspergillus sp. Cepa Y/As-3 y Rhizomucor sp. Cepa 1A/R-1. Sobre suelo contaminado con petróleo.

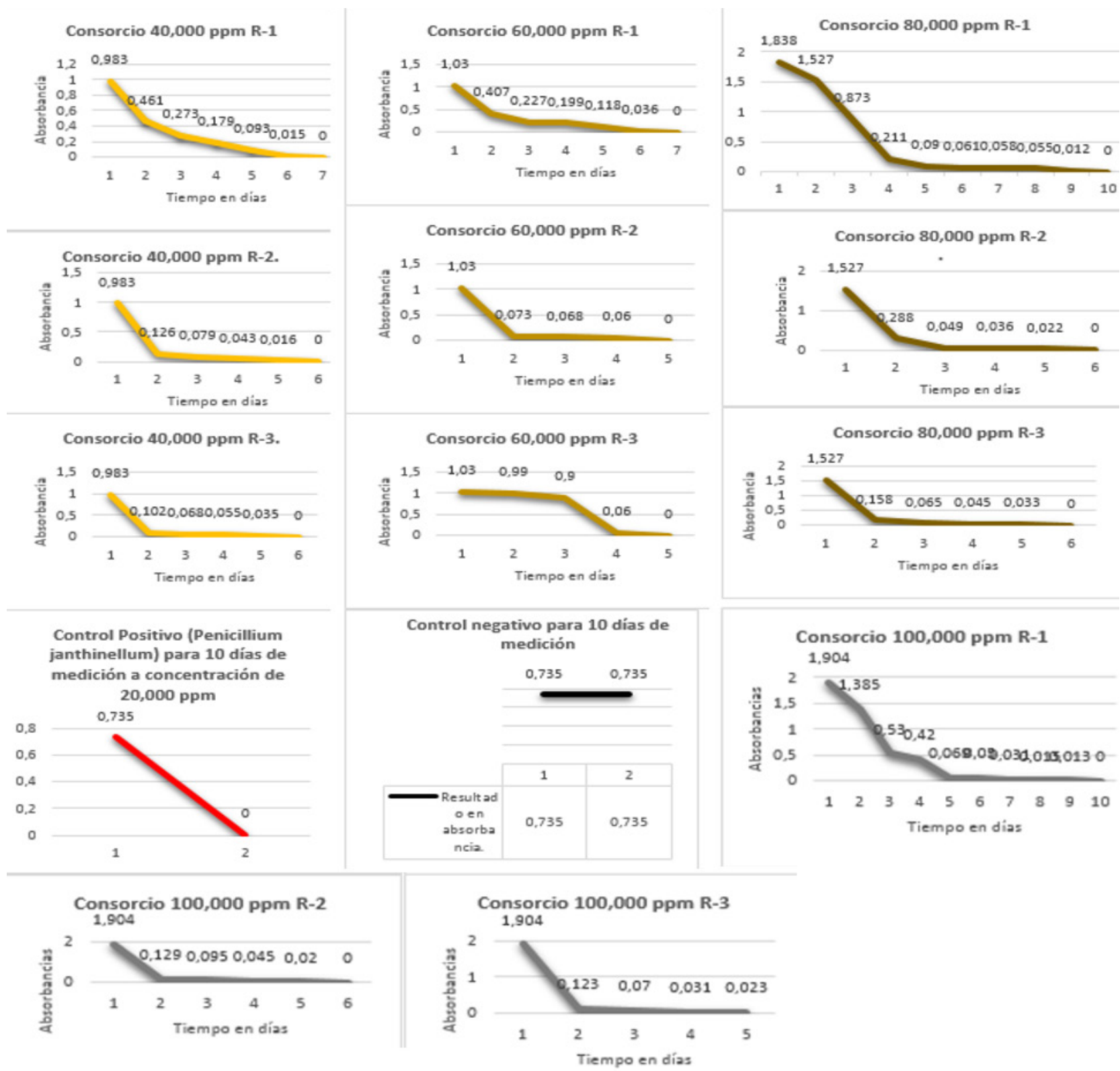

Fuente. Elaboración propia.

1: Aplicación de los tres géneros de hongos a nivel individual: los resultados obtenidos al evaluar la capacidad biorremediadora de los tres hongos filamentosos, se presenta en las siguientes figuras y tablas. En la Figura 4 se puede observar que no hay diferencia significativa entre los tres géneros utilizados, ya que su capacidad biorremediadora sobre suelo contaminado con petróleo crudo se llevó a cabo un periodo entre 5 a 6 días. 
Figura 4. Efectividad biorremediadora de los hongos Neosartorya sp. Cepa A/N-1, Aspergillus sp. Cepa Y/As-3 y Rhizomucor sp. Cepa 1A/R-1, sobre suelo contaminado con petróleo crudo a $20.000 \mathrm{ppm}$.

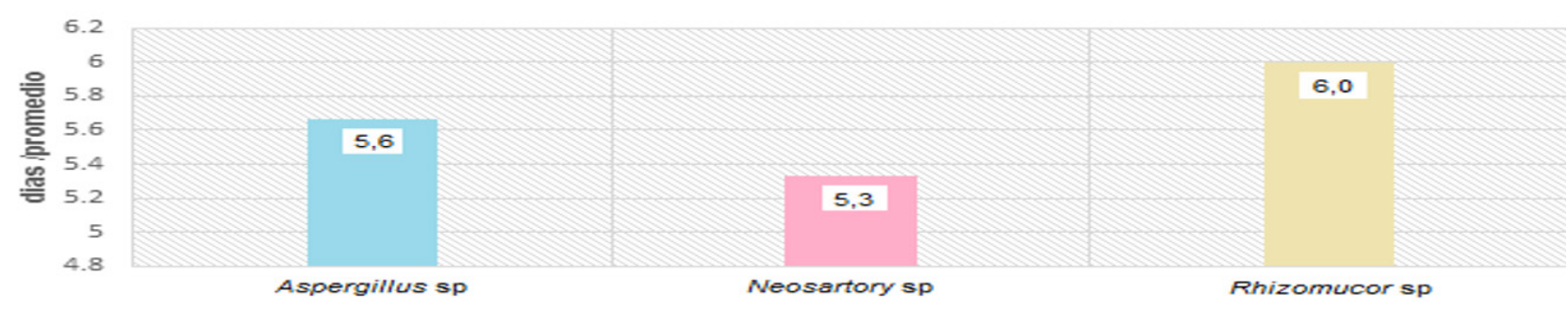

Fuente. Elaboración propia.

En la Figura 5 se puede observar que no existe dife- Aspergillus sp. Cepa Y/As-3 y Rhizomucor sp. Cepa rencia entre el tiempo que necesitan los géneros de 1A/R-1, para biorremediar el petróleo crudo del hongos filamentosos Neosartorya sp. Cepa A/N-1, suelo contaminado artificialmente a $30.000 \mathrm{ppm}$.

Figura 5. Efectividad biorremediadora de los hongos Neosartorya sp. Cepa A/N-1, Aspergillus sp. Cepa Y/As-3 y Rhizomucor sp. Cepa 1A/R1 , sobre suelo contaminado con petróleo crudo a $30.000 \mathrm{ppm}$.

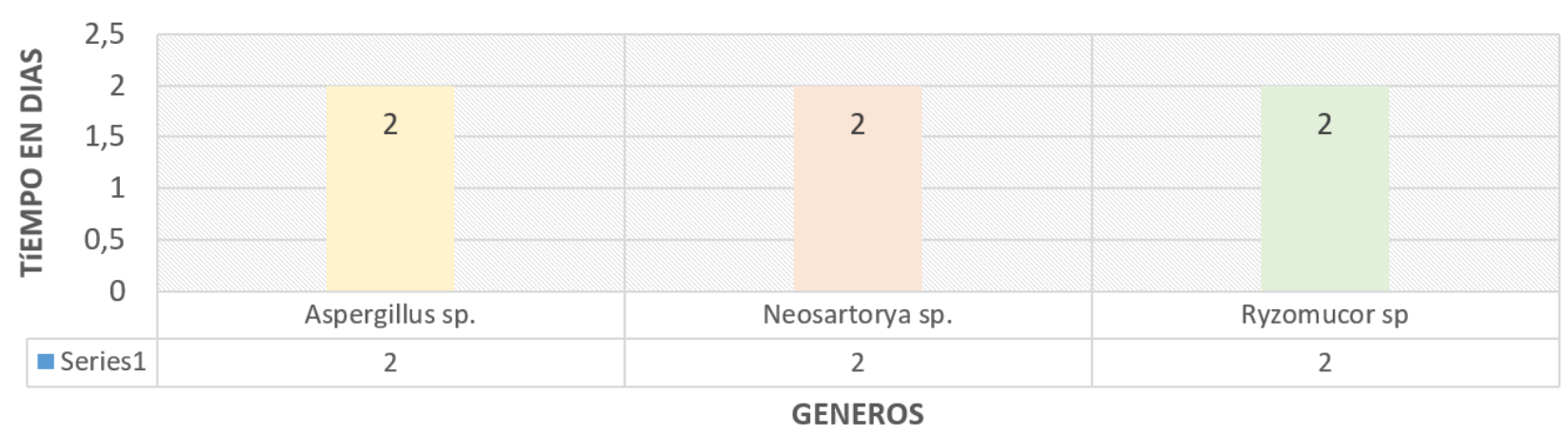

Fuente. Elaboración propia.

En la Tabla 3 se consolida la evidencia encontrada donde se puede verificar que no existe diferencia entre géneros frente a la capacidad biorremediadora de los mismos. Sin embargo, sí se verifica que hay una respuesta diferencial frente a la concentración de petróleo $(\mathrm{p} \leq 04 \mathrm{e}-12)$, la cual se reporta en la Tabla 10 (HSD para concentraciones). 
Tabla 3. Resultados obtenidos en la ANOVAs para los análisis aplicados a los tres géneros Neosartorya sp. Cepa A/N-1, Aspergillus sp. Cepa Y/ As-3 y Rhizomucor sp. Cepa 1A/R-1.

\begin{tabular}{|l|l|l|l|l|l|}
\hline \multicolumn{1}{|c|}{$\begin{array}{c}\text { Fuente de } \\
\text { Variación }\end{array}$} & \multicolumn{1}{|c|}{ Df } & \multicolumn{1}{c|}{ Sum } & \multicolumn{1}{c|}{ Sq Mean } & \multicolumn{2}{c|}{ Sq F value } \\
\hline Género & 2 & 3.93 & 1.97 & 1.871 & 0.166 \\
\hline $\begin{array}{l}\text { Concentración } \\
\text { del petróleo }\end{array}$ & 1 & & 93.68 & 89.163 & $3.04 \mathrm{e}-12^{* * *}$ \\
\hline $\begin{array}{l}\text { Género } x \\
\text { Concentración } \\
\text { del petróleo }\end{array}$ & 2 & 0.79 & 0.40 & 0.377 & 0.688 \\
\hline Residuals. & 45 & 47.28 & 1.05 & & \\
\hline
\end{tabular}

Fuente. Elaboración propia.

En la prueba de Diferencia Honesta Significativa o Tukey, agrupamiento $a$ en la Tabla 4, se puede observar que con una concentración de $30.000 \mathrm{ppm}$, el tiempo tuvo un promedio de digestión que disminuyó a la mitad, lo que equivale a 2.8 días. Esto indica que para los tres géneros de hongos utilizados en la biorremediación del petróleo crudo en suelo es más favorable su acción en una concentración de $30.000 \mathrm{ppm}$.

Tabla 4. Diferencia Honesta Significativa o Tukey para los análisis aplicados a los tres géneros Neosartorya sp. Cepa A/N-1, Aspergillus sp. Cepa Y/As-3 y Rhizomucor sp. Cepa 1A/R-1.

\begin{tabular}{|l|l|l|}
\hline Concentración petróleo crudo en la muestra & \multicolumn{1}{|c|}{ Promedio } & \multicolumn{1}{|c|}{ Agrupamiento } \\
\hline 30.000 & 2.8 & $\mathrm{a}$ \\
\hline 20.000 & 5.806 & $\mathrm{~b}$ \\
\hline
\end{tabular}

Fuente. Elaboración propia.

Así mismo se puede establecer que no hay diferencia significativa entre las absorbancia en función de la concentración ni del hongo, mientras que el tiempo de respuesta si evidenció diferencias como función de las concentraciones.

\section{2: Aplicación de los tres géneros de hongos en con-}

sorcio: los resultados obtenidos en este proyecto y detallados en la Figura 6 permiten evidenciar que la evaluación de la capacidad biorremediadora en concentraciones de petróleo crudo de $40.000 \mathrm{ppm}$ y $60.000 \mathrm{ppm}$, transcurre en un promedio de 6.4 días y en concentraciones de petróleo crudo de $80.000 \mathrm{ppm}$ y $100.000 \mathrm{ppm}$ se realiza en un promedio de 8.9 días, teniendo mejor respuesta los dos tratamientos iniciales con relación a los últimos. 
Figura 6. Efectividad biorremediadora del consorcio comprendido por los géneros Neosartorya sp. Cepa A/N-1, Aspergillus sp. Cepa Y/As-3 y Rhizomucorsp. Cepa 1A/R-1.

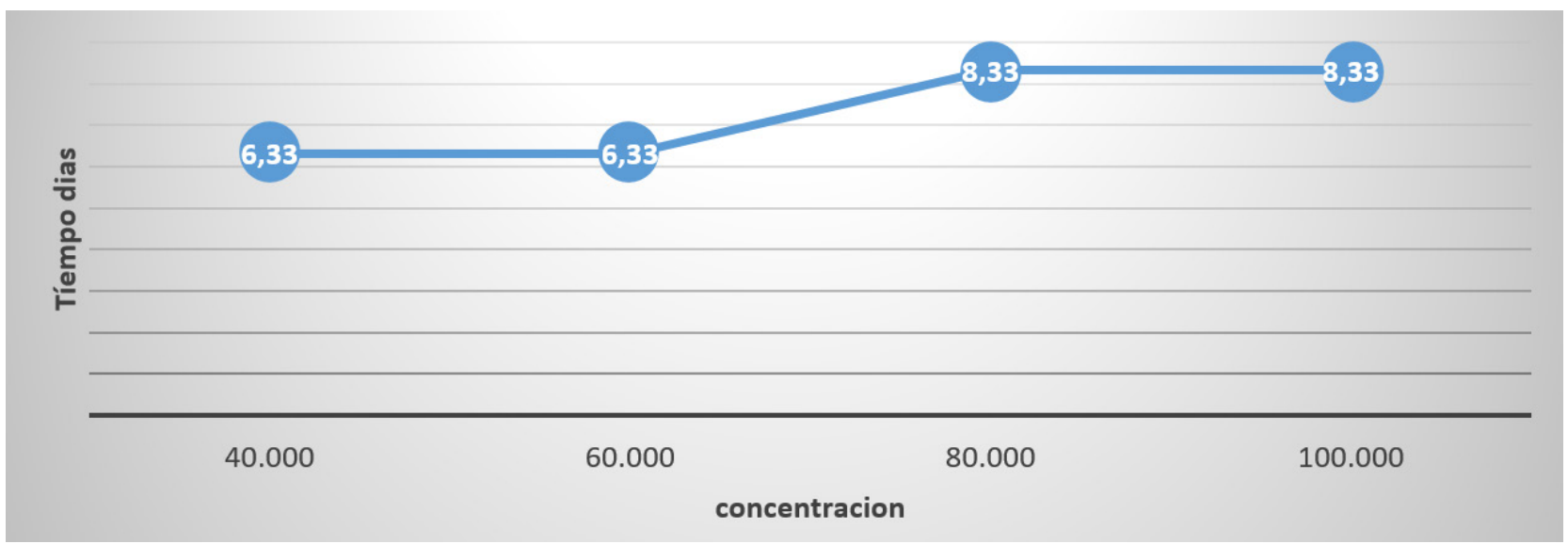

Fuente. Elaboración propia.

En la Tabla 5, la cual corresponde a la ANOVA diadora es diferente en función de la concentración para el consorcio conformado por los géneros de petróleo. Puede verificarse que en la medida en Neosartorya sp. Cepa A/N-1, Aspergillus sp. Cepa que la concentración es mayor, existe una actividad Y/As-3 y Rhizomucor sp. Cepa 1A/R-1, se aporta biorremediadora más rápida como se registra en la evidencia de que el tiempo de actividad biorreme- Tabla 6 (HSD).

Tabla 5. Resultados obtenidos en ANOVAs para el consorcio conformado por los géneros Neosartorya sp. Cepa A/N-1, Aspergillus sp. Cepa Y/As-3 y Rhizomucor sp. Cepa 1A/R-1.

\begin{tabular}{|l|l|l|l|l|l|}
\hline $\begin{array}{c}\text { Fuente de } \\
\text { Variación }\end{array}$ & \multicolumn{1}{|c|}{ Df } & \multicolumn{1}{|c|}{ Sum } & \multicolumn{1}{|c|}{ Sq Mean } & \multicolumn{1}{|c|}{ Sq F value } & \multicolumn{1}{c|}{$\operatorname{Pr}(>$ F $)$} \\
\hline $\begin{array}{l}\text { Concentración } \\
\text { del petróleo }\end{array}$ & 3 & 104.4 & 34.79 & 14.02 & $3.96 \mathrm{e}-07^{* * *}$ \\
\hline Residuals & 64 & 158.8 & 2.48 & & \\
\hline
\end{tabular}

Fuente. Elaboración propia.

Tabla 6. Diferencia Honesta Significativa o Tukey para el consorcio conformado por los géneros Neosartorya sp. Cepa A/N-1, Aspergillus sp. Cepa Y/As-3 y Rhizomucor sp. Cepa 1A/R-1.

\begin{tabular}{|l|l|l|}
\hline \multicolumn{1}{|c|}{ Concentración petróleo crudo en la muestra } & \multicolumn{2}{c|}{ promedio } \\
\hline 40.000 & 6.375 & a \\
\hline 60.000 & 6.429 & b \\
\hline 80.000 & 8.895 & c \\
\hline 100.000 & 8.895 & c \\
\hline
\end{tabular}

Fuente. Elaboración propia. 
En la Tabla 6 también se evidencia que el uso de hongos filamentosos como Neosartorya sp. Cepa A/N-1, Aspergillus sp. Cepa Y/As-3 y Rhizomucor $s p$. Cepa 1A/R-1, en consorcio, muestran un efecto sinérgico entre estos y que pueden degradar petróleo crudo de alta densidad ( ${ }^{\circ}$ API de 21.6) en concentraciones entre $40.000 \mathrm{ppm}$ hasta $100.000 \mathrm{ppm}$, en un tiempo promedio de 6 a 8 días, en un porcentaje de $100 \%$.

Resultado de la evaluación cualitativa in vitro del mecanismo de acción enzimático de los géneros de hongos filamentosos utilizados en la biorremediación de petróleo crudo pesado: en este proyecto se identificó cualitativamente el uso de peroxidasa (lignina peroxidasa) como mecanismo de acción de las tres especies evaluadas, lo cual indica que usaron enzimas peroxidasas en el metabolismo bioquímico empleado por las especies de hongos utilizados para evaluar la capacidad biorremediadora. Se puede corroborar que el metabolismo fúngico es de tipo aeróbico, garantizando al final del proceso la producción de biomasa, liberación de $\mathrm{CO} 2$ y agua.

Resultado de la prueba de citotoxicidad realizada a los hongos filamentosos seleccionados en el proyecto de biorremediación: no se encontró evidencia en el tejido vegetal de la planta Allium fistulosum, por lo que se considera que los hongos filamentosos utilizados en el proyecto carecen de citotoxicidad. Vale la pena resaltar que cuando la planta está en presencia de agua con alguna sustancia tóxica o en presencia de un microorganismo patógeno se inhibe la división celular de los meristemos, afectando parcial o totalmente el proceso de mitosis (68).

\section{Discusión}

A partir del desarrollo de esta investigación se pudo apreciar que hay diferencias en algunas de las características físico-químicas en los suelos analizados con respecto a los resultados obtenidos en las muestras control. Con respecto a los conteni- dos de hidrocarburos, se encontró que la muestra de Yondó presentó una concentración de 0,797 $\%$ de hidrocarburos, la muestra de Acacías (Meta) el valor registrado fue de $0,931 \%$ y la muestra de Tumaco (Narińo) el valor fue de 1,02\% de hidrocarburos. Es importante anotar que no existe una norma específica en Colombia que haga referencia a los valores máximos permisibles de hidrocarburos en suelo. La única resolución que trata este tema es la 631 del 17 de marzo de 2015, expedida por el Ministerio de Ambiente y Desarrollo Sostenible dirigida a vertimientos de aguas residuales. Por lo tanto, para este documento se toma como referencia el tratado de Luisiana, el cual señala a las muestras analizadas como contaminadas con hidrocarburos (69).

Las muestras control corresponden a suelos no contaminados con hidrocarburos, con concentración por debajo del $0,02 \%$, lo cual según la técnica de gravimetría corresponde a valores por debajo de la sensibilidad de la técnica utilizada y por tanto los suelos control no presentan contaminación con hidrocarburos (69). En cuanto a la conductividad eléctrica en las muestras y controles permiten observar que son suelos extremadamente salinos o fuertemente salinos y por último los valores en amonio, fosfatos nitratos y nitritos en las muestras de suelo contaminadas y evaluadas son muy pobres y difieren de las muestras control (48).

Posterior a la siembra de los hongos encontrados y mencionados en la Tabla II, se puede observar que de 138 cepas aisladas en 90 cultivos primarios de las muestras de suelo contaminado con petróleo crudo localizados en los municipios de Yondó (Antioquia), Acacías (Meta) y Tumaco (Nariño); identificados a partir de sus características macroscópicas y microscópicas, con la ayuda de las claves taxonómicas de $(45,46,47)$, así como la amplificación por PCR de la región ITS, se estableció que pertenecían a siete géneros de hongos filamentosos que son: Aspergillus sp., Penicillium sp., Neosartorya sp., Phoma sp., Rhizomucor sp., Mucor sp., y Absidia $s p$. 
Godoy y colaboradores (70) aislaron de suelo contaminado con hidrocarburos 23 especies de hongos pertenecientes en su mayoría a la Phylum Ascomycota, Phylum Basidiomycota y la subfilo mucoromycotina, los cuales degradaron el anillo antraceno en 42 días por medio de enzimas extracelulares oxidorreductasa. Varias de estas especies liberaron al contacto con el contaminante. Destaca la capacidad de la mayoría para degradar totalmente el hidrocarburo y solo unas pocas parcialmente, con porcentaje superior al 90\%. La mayor parte de las cepas de hongos filamentosos encontradas en suelos contaminados con petróleo crudo en este proyecto pertenecen a los géneros Aspergillus sp. y Penicillium sp., las cuales, según la literatura, son las especies más utilizadas en el campo de la biorremediación ya que han sido obtenidas en muestras de suelo y agua contaminada con petróleo crudo y derivados de éste, en diversas partes del planeta como Indonesia (71); desierto de Kuwait, (72); el desierto de Arabia Saudita (73); Argentina (74); Guanaco, estado de Sucre en Venezuela (75); Nigeria (76); el Golfo de México (77) e Irán (28,78); lo cual indica su poder biorremediador de suelos, su carácter cosmopolita y una amplia capacidad de adaptarse a todos los climas, condiciones edáficas y atmosféricas $(13,78,79,80)$.

Este proyecto respalda lo dicho por muchos investigadores como Sawulski y colaboradores (2), quienes analizaron la comunidad microbiana presente en suelos contaminados con diferentes tipos de hidrocarburo y su comportamiento a partir del contacto con este, destacando las pocas especies que sobreviven a este impacto y cómo las especies que se adaptan poseen capacidad hidrocarburolítica. Silva y colaboradores (32) utilizaron en su proyecto microorganismos aislados de un sustrato contaminado previamente con diésel y encontraron que las especies aisladas en dicho sustrato tienen capacidad para degradar en algún grado dicho contaminante. Aranda (81) destaca la importancia de utilizar especies de hongos por su potencial capacidad biorremediadora de petróleo crudo y derivados. Afirma, además, que su metabolismo in- tracelular es complejo y poco estudiado, pero que a partir del estudio del genoma de estos se podría aplicar su sistema enzimático, el cual está presente en casi todas las especies.

Así mismo se encontró en esta investigación el hongo filamentoso perteneciente al género Neosartorya, el cual se aisló inicialmente de suelos contaminados con petróleo crudo por lo que se considera una especie con capacidad biorremediadora (69, $73,78,79,80,82)$. Y precisamente es en el estudio de Uribe y colaboradores (83) donde se comenta que hay evidencia de la capacidad que posee $N$. fischeri para mineralizar asfáltenos, catabolizando más del 15\% del carbono presente en esta sustancia en un tiempo aproximado de 11 semanas; estudio que pudo ser la base de los proyectos de Hernández y colaboradores (84), quienes realizaron la transcripción de los perfiles utilizando un diseño propio de microarray, con el cual identificaron los genes que le permiten a esta especie utilizar los asfáltenos como única fuente de carbono. Ke y colaboradores (85) clonaron una endo y exo poligalacturonasa a partir de esta especie, para obtener dicha enzima in vitro ya que ésta se caracteriza por ser estable a una temperatura de $55^{\circ} \mathrm{C}$ y tolerar un amplio rango de $\mathrm{pH}$; lo cual permite su uso en procesos de biorrefinería. Cabe destacar que este género de hongo filamentoso, no había sido reportado en suelos contaminados con petróleo crudo en Colombia hasta la presente investigación.

Otros géneros encontrados en el proyecto son: Phoma sp., Mucor sp., y Absidia sp., los cuales fueron reportados como biorremediadores de petróleo crudo en un estudio realizado por Yuan y colaboradores (86). Passarini (29) describieron como el género Mucor sp., posee una actividad enzimática como el mecanismo para degradar las cadenas lineales y ramificadas a sustancias como el $\mathrm{CO}_{2}$ y $\mathrm{H}_{2} \mathrm{O}$. Resultado confirmado en la investigación liderada por Pernia y colaboradores (82) establecieron la capacidad biorremediadora en suelos contaminados con cadmio y petróleo crudo. En relación al género Rhizomucor, no se encontraron, al finali- 
zar el año 2016, reportes como agente hidrocarburolítico, salvo lo encontrado en esta investigación.

Con base en lo obtenido por el ANOVA, se puede decir que en procesos de biorremediación con el método de Landfarming modificado, el uso de hongos filamentosos como son Neosartorya sp. cepa A/N-1, Aspergillus sp. cepa Y/As-3 y Rhizomucor $s p$. cepa $1 \mathrm{~A} / \mathrm{R}-1$, cuando se utilizan por separado o en consorcio es una opción ecológica, económica y rápida para la recuperación de suelo contaminado, ya que se evidencia un efecto sinérgico entre estos y pueden degradar petróleo crudo de alta densidad ( ${ }^{\circ}$ API de 21.6) en concentraciones entre $20.000 \mathrm{ppm}$ hasta $100.000 \mathrm{ppm}$, en un tiempo promedio de 6 a 8 días, dependiendo de la concentración del petróleo crudo en un porcentaje de $100 \%$. Sarkar y colaboradores (87) realizaron una comparación entre dos métodos de biorremediación, Por una parte, la bioestimulación aplicando nitrógeno, fósforo inorgánico y biosólidos. Por otra, el método de atenuación natural, adicionando nitrógeno y fosforo inorgánicos, en un suelo de tipo arcilloso contaminado con diésel. En ambos casos el experimento se llevó a cabo in vitro. Después de 8 semanas de bioestimulación obtuvieron una degradación del contaminante de $96 \%$ para el método de bioestimulación y para el método de atenuación natural el resultado fue superior al 93\% lo cual, concuerda con lo realizado por Naranjo y colaboradores (75), quienes utilizaron los géneros mencionados en este proyecto al sembrarlos en medio de cultivo con petróleo crudo como sustrato contaminante, con el fin de obtener enzimas extracelulares capaces de degradar el hidrocarburo, en 21 días aproximadamente, en un porcentaje superior al $70 \%$. Es importante destacar que varios estudios en este campo aseguran que es difícil biorremediar suelo o agua contaminados con petróleo crudo por su alto peso molecular y por los anillos bencílicos (89). Se necesita de una fuerte reacción por parte del hongo filamentoso con enzimas extracelulares para romper dichos anillos y mineralizar esta sustancia hasta hacerla inocua para cualquier ser vivo (84).
Posterior a dicha investigación, Taewoo y colaboradores (89) afirmaron que la Neosartorya sp. es un organismo de fácil recuperación en componentes naturales afectados por petróleo crudo y es un género que no posee una fase de latencia, capaz de metabolizar petróleo crudo de alta densidad, así como derivados de éste, aunque su capacidad biorremediadora se observa mejor en concentraciones del contaminante entre 5.000-20.000 mg/L. Además, comentaron que la capacidad de la Neosartorya sp. De adaptar su actividad metabólica, lo hace al utilizar diferentes tipos de hidrocarburos como un donador de electrones; lo cual concuerda con lo observado en este proyecto cuando se aplicó la cepa Neosartorya sp. Cepa A/N-1; observándose una rápida respuesta en la biorremediación del suelo contaminado.

Jia y colaboradores (94) aislaron de suelo contaminado con petróleo crudo catorce cepas de hongos filamentosos, las cuales se identificaron por medio del análisis de PCR amplificando la región ITS como géneros pertenecientes a Fusarium sp., Bionectria sp., Stachybotrys sp., Aspergillus sp., y Actinomucor sp. Para su estudio se dividieron las cepas en dos grupos y los resultados mostraron que las cepas podrían degradar diferentes componentes de petróleo crudo, lo cual fue evaluado por GC-MS. La capacidad biorremediadora se evaluó por 30 días en un medio líquido con el petróleo crudo y la tasa de biorremediación fue de 74,55\% y 72,64\%, respectivamente. Maddela y colaboradores (95) aislaron del suelo contaminado con petróleo crudo dos cepas de hongos filamentosos pertenecientes al género Geomyces sp., las cuales aplicaron a suelos en ambiente controlado como es un microcosmos contaminado con petróleo crudo en concentraciones de $1 \%$ y $1,5 \%$; además, adicionaron $\mathrm{N}, \mathrm{P}, \mathrm{K}$, para estimular el crecimiento del hongo inicialmente, por un periodo de 30 días, evaluando el proceso por cromatografía de gases y determinaron que el proceso de biorremediación se realizó en un porcentaje de $73,3 \%$ a $79,9 \%$ respectivamente. Los equipos de Fuad (13) y Benyahia (96) destacaron la efectividad de los hongos en biorremediación de diésel 
cuando se aplican en consorcio y Manli y colaboradores (97) obtuvieron resultados en el desarrollo de su investigación en la medición de la capacidad biorremediadora de hongos filamentosos para una efectividad en 70 días de $60 \%$ de degradación del contaminante y al cabo de 156 días de 77\%.

En cuanto a la actividad enzimática de los hongos filamentosos, esta se basa en el estudio de los mecanismos de acción, tanto intracelular como extracelular y aunque no se tiene bien identificada cada una de estas rutas, se sabe que son de tres tipos, lignino-oxidasas, lignino-peroxidasas y lignino-hidrolasas como han mostrado Johnsen y colaboradores (98). Mohsenzadeh y Chehregani (28) midieron la producción enzimática de hongos filamentosos para remediar diferentes concentraciones de petróleo crudo, para lo cual solo tuvo en cuenta enzimas como la catalasa, el fenol-oxidasa y la peroxidasa, determinando que a mayor concentración del petróleo crudo, hay mayor actividad peroxidasa. Ali y colaboradores (79) encontraron como mecanismo enzimático para el proceso de biorremediación de diésel las enzimas lignina-peroxidasas. Deshmukh y colaboradores (99) resaltaron la producción enzimática de los hongos filamentosos, la importancia de aquéllas y la futura aplicabilidad desde el campo de la biotecnología. Mohsenzadeh y Shirkhani (100) aislaron siete cepas de hongos filamentosos en la refinería de petróleo de Teherán, pertenecientes al género Aspergillus sp., en el medio de cultivo PDA con una concentración de petróleo crudo entre $0-15 \%(v / v)$. Posterior al crecimiento determinaron la producción de las enzimas extracelulares como son la peroxidasa y catalasa como mecanismo para la biorremediación. Estos resultados podrían confirmar los obtenidos en los estudios realizados por Fuad y colaboradores (13), quienes destacaron el uso de enzimas extracelulares como la lignina-peroxidasas así como la liberación de $\mathrm{CO}$ al final de proceso de remediación y la producción de una alta cantidad de biomasa en dicho proceso. Además, no se encontró evidencia en el tejido vegetal de la planta Allium fistulosum de alteraciones morfo-fisiológicas, por lo que se considera que los hongos fila- mentosos Neosartorya sp. Cepa A/N-1, Aspergillus $s p$. Cepa Y/As-3 y Rhizomucor sp. cepa 1A/R-1, no presentaron fitotoxicidad, de acuerdo con la prueba desarrollada en la investigación, por lo que son adecuadas en procesos de micorremediación, cuando la planta está en presencia de agua con alguna sustancia tóxica o en presencia de un microorganismo patógeno (68).

El uso de los carbonos presentes en el petróleo crudo como fuente de energía para algunas especies de hongos filamentosos permite la aplicación de estos en la biorremediación de suelos y aguas contaminados (90-93). Al finalizar esta investigación, se concluyó que de 138 cepas aisladas en 90 cultivos que corresponden a siete géneros de hongos filamentosos, con capacidad biorremediadora de suelo contaminado con petróleo crudo pesado o derivados de este, los hongos filamentosos Neosartorya sp. Cepa A/N-1, Aspergillus sp. Cepa Y/As-3 y Rhizomucor sp. cepa $1 \mathrm{~A} / \mathrm{R}-1$ son capaces de biorremediar petróleo crudo pesado en un tiempo promedio entre 2 a 10 días, con una efectividad de $100 \%$ por medio de la enzima extracelular perteneciente al grupo de lignina-peroxidasa (101-103). Vale la pena destacar que en los tres sitios muestreados se aislaron ocho cepas pertenecientes al género Neosartorya sp., y esta especie no había sido reportada como biorremediador de petróleo crudo en Colombia. Además en el desarrollo de este proyecto se identificaron siete cepas correspondientes al género Rhizomucor sp. Este género no había sido reportado como agente biorremediador de petróleo crudo, en este proyecto se pudo comprobar su potencial uso en este campo.

\section{Conflicto de intereses}

Los autores declaran que no tienen conflicto de interés. 


\section{Referencias}

1. Ruiz O, Brown L.; Striebich R.; Inteligente C.; Bowen L.; Lee J.; Little B.; Mueller S.; Gunasekera, T. (2016). Effect of conventional and alternative fuels in a bacterial marine environment and the importance of bioremediation. Journal of the American Chemical Society. 30 (1) 434-444.

2. Sawulski, P., Clipson, N., Doyle, E. (2014). Effects of polycyclic aromatic hydrocarbons on microbial community structure and $\mathrm{PAH}$ ring hydroxylating dioxygenase gene abundance in soil. Biodegradation. 25. 6: 835-847.

3. Tian, W., Zhao, Y., Sun, H., Bai, J., Wang, Y., Wu, C. (2014). The effect of irrigation with oil-polluted water on microbial communities in estuarine reed rhizosphere soils. Ecological Chemistry and Engineering. 70, 275-281.

4. Verma T, Baiswar V. (2013). Isolation and characterization of extracellular thermoalkaline protease producing Bacillus cereus isolated from tannery effluent. International Journal Environmental Science. 2: 23-29

5. Vallejo, V., Salgado, L. Y Roldán, F. (2005). Evaluación de la bioestimulación en la biodegradación de TPHs en suelos contaminados con petróleo. Revista Colombiana de Biotecnología 2 (2): $67-78$.

6. Siva, S.; Brett, R.; Tessa, M.; Vogeler, I.; Clothier, B.; Grant, L.; Northcot, T.; Mcnaughton, D. (2004). Bioremediation of soils contaminated with organic compounds. Disponible en: http: //www.regional.org.ou/au/asssi/supersoil2004/ pdf/1455_sivakumaranspdf (Consultado el 7/07/2014)

7. Restrepo R. (2002). Derrame de hidrocarburos. Impacto en los ecosistemas tropicales. ECOPETROL Instituto Colombiano de Petróleo.

8. González C. (2011). Renta minera, petróleo y comunidades. INDEPAZ. Bogotá, D.C. Colombia.

9. ECOPETROL. (2015). Oleoductos en Colombia, disponible desde internet desde:http://www.ecopetrol.com.co/wps/ portal/es/ecopetrol-web/nuestra-empresa/quienes-somos/ lo-que-hacemos/transporte.

10. Benavides L.; Quintero G.; Guevara V.; Jaimes D. (2006). Bioremediación de suelos contaminados con hidrocarburos derivados del petróleo. Colombia. Nova. 4 (5):1-116

11. Shanidul I. Y Tanaka M. (2004). Impacts of pollution on coastal and marine ecosystems including coastal and marine fisheries approach for management: a review and synthesis. Marine Pollution Bulletin. 48: 624-649.

12. Wang X.; Wang X.; Liu M.; Bu Y.; Zhang J.; Chen J.; Zhao J. (2015). Adsorption-synergic biodegradation of diesel oil in synthetic seawater by acclimated strains immobilized on multifunctional materials. Marine Pollution Bulletin 92: (15)195200.

13. Fuad A.; Mohamed M.; Sarfaraz H.; Ahmed E.; Al-Sabri. (2015). Biodegradation of diesel fuel hydrocarbons by mangrove fungi from Red Sea Coast of Saudi Arabia Department of Botany \& Microbiology, Faculty of Science, King Saud University, Riyadh 11451. Saudi Arabia.
14. Agrios G. (2005). Plant pathology. Elsevier Academic Press. Fifth edition. Amsterdam. 948 p.

15. Schmidt, W. (2000). Suelos contaminados con hidrocarburos: la biorremediación como una solución ecológicamente compatible. Cooperación Técnica Alemana. (GTZ) Disponible en internet en: www.gtz.org.mx/sitios_contam/articulos/biorremed_Mexz.pdf. (con acceso el 30/10/2012)

16. Garcia E.; Zavala J.; Palma D. (2006). Caracterización de las comunidades vegetales en un área afectada por el derrame de hidrocarburos. Terra latinoamericana. Universidad Autónoma de Chapingo. México. 21 (1): 17-26.

17. Ugochukwu, C. 2015. Biodegradation of crude oil saturated fraction supported on clays. Universidad de California. Biodegradation. Fialips. Vol. 25 1:153-165.

18. Biswas B.; Sarkar B.; Mandal A.; Naidu R. (2015). Heavy metal-immobilizing organ clay facilitates polycyclic aromatic hydrocarbon biodegradation in mixed-contaminated soil. Journal of Hazardous Materials, 298: 129-137.

19. Castillo C.; Abuelo A.; Hernández J. (2016). El desafío de la metanogénesis en bovinos. Departamento de patología animal. Universidad de Santiago de Compostela. School of animal \& Veterinaria Science. Charles start University Australia.

20. Montoya S.; Sanchez O.; Levin L. (2014). "Mathematical Modeling of Lignocellulolytic Enzyme Production from Three Species of White Rot Fungi by Solid-State Fermentation” Advances In Computational Biology Proceedings. Springer International Publishing Switzerand. $371-377$.

21. Martínez M.; Ruiz-Dueñas F.; Guillén F.; Martínez, A. (1996). Purification and catalytic properties of two manganese-peroxidase isoenzymes from Pleorotus eryngii. European Journal of Biochemistry.237: 424-432.

22. Tortella G, Duran N, Rubilar O, Parada M, Diez M.C. (2015).Are witerot fungi a real biotechnological option for the improvement of environmental health? Critical reviews in biotechnology.35 (2) 165-172.

23. Bolívar F. (2002). Biotecnología moderna para el desarrollo de México en el siglo XXI. Retos y oportunidades. CONACYT y Fondo de Cultura Económica. 187-207.

24. Quintero R. (1981). Ingeniería Bioquímica: Teoría y Aplicaciones. Alambra Mexicana. México.15-17.

25. Lema R.; Roca B. (1998). Biorreactores no convencionales. En Ingeniería Bioquímica, Editorial Síntesis. 189-214.

26. Sagardoy M.; Mandolesi M. (2004). Biología del suelo guía de estudio. Editorial de la Universidad Nacional del Sur. Ediuns 2 ed. Argentina.

27. Urrea E, Garcia-Romero I, Aranda E. (2015). Potential of non-ligninolytic fungi in bioremediation of chlorinated and polycyclic aromatic hydrocarbons. New Biotecnology. 33(6) 620-628.

28. Mohsenzadeh F, Chehregani R, Akbari M. (2012). Evaluation of oil removal efficiency and enzymatic activity in some fungal strains for bioremediation of petroleum-polluted soils Iran. Journal Environmental Health Science Engineering. 9: 26. 
29. Passarini M.; Rodríguez M.; Da Silva M.; Siete L. (2011). Marine derived filamentous fungi and their potential application for polycyclic aromatic hydrocarbon bioremediation. Marine pollution Bulletin 62: (2)364-370.

30. Mohan S.; Srivastava T. (2010). Microbial deterioration and degradation of polymeric materials. Journal Biochemistry Technology. 2: 210-215.

31. Majcherczyk A, Johannes C, Huttermann A. (1998). Oxidation of polycyclic aromatic hydrocarbons $(\mathrm{PAH})$ by lacasse of trametes versicolor: Enzyme and Microbial Technology-Journal 22: 335-341.

32. Silva G, Holdt Sl, Birkeland Mj, Angelidaki I. (2015). Commercial cultivation and bioremediation potential of sugar kelp, Saccharina latissima, in Danish waters. Journal of Applied Phycology. 27(5):1963-1973.

33. Ruberto L.; Vazquez S.; Dias R.; Hernández E.; Coria S.; Levin G.; Lo Balbo A.; Mac Cormack W. (2010). Small-scale studies toward a rational use of bioaugmentation in an Antarctic hydrocarbon-contaminated soil. Antarctic Science. 22 (5):463-469.

34. Lin, T ; Panb, P. ; Cheng, S. (2010). Ex situ bioremediation of oil-contaminated soil. Journal of Hazardous Materials. 176:27-34.

35. Crawford J.; Traina S.; Touvinen O. (2000). Bacterial degradation of atrazine in redox potential gradients in fixed-film sand columns. Soil Science Society of America Journal 64(2): 624-634.

36. Boyd D.; Sharma R.; Allen C. (2001). Dioxigenasas aromáticas: biocatálisis molecular y aplicaciones. Current Opinion in Biotechnology. 12 (6): 564-573.

37. Bühler B.; Schimd A.; Hauer B.; Witholt B. (2000). Xylene monooxygenase catalyzes the multistep oxygenation of toluene and pseudocumene to corresponding alcohols, aldehydes, and acids in Escherichia coli JM101. Journal of Biological Chemistry. 275 (14): 10085-10092.

38. Pallarez M, (2015). Tipos de suelos y formas de tratarlos a favor de la ganadería. noviembre 9 de 2015. Revista Contexto ganadero. FEDEGAN. Bogotá. Revisado el 20 de enero de 2016.Tomado de: http://contextoganadero.com/reportaje/ revisada-tipos-de-suelos-y-formas-de-tratarlos-favor-de-la-ganaderia.

39. IDEAM (2015). Promedio de la temperatura disponible desde internet desde: http://www.ideam.gov.co/web/tiempo-y-clima/seguimiento-tiempo.

40. FEDEGAN. (2015). Tipos de suelos y formas de tratarlos a favor de la ganadería publicado noviembre 9 de 2015. Revista Contexto ganadero. FEDEGAN. Bogotá.

41. Burlange R.; Atlas R.; Stahl D.; Geesey G.; Sayler G. (1998). Techniques in Microbial Ecology Ox Ford University Press. 239-242.

42. Ferraris G. (2000). Muestreo y análisis de suelos. Facultad de Agronomía Universidad de Buenos Aires Argentina. Disponible desde internet en: http://www.elsitioagricola.com/arti-
culos/ferraris/Muestreo\%20y\%20Analisis\%20de\%2. (Con acceso el 24/04/ 2014)

43. Norma Tecnica Colombiana 4113-6. (1997). Gestión ambiental. Calidad de suelo. Muestreo. Guía para la recolección, manejo y almacenamiento de suelo para la evaluación de procesos microbiológicos aeróbicos en el laboratorio.

44. Valencia, H. (1979). La microbiología del suelo y sus perspectivas. Departamento de biología Universidad Nacional de Colombia. Boletín informativo 1:1-18.

45. Alexopoulos C.; Mims C.; Blackwell M. (1996). Introductory mycology. Cuarta edición. Jhohan Wiley \& Sons. Nueva York. 829 p.

46. Barnett H.; Hunter B. (1972). Ilustrated Genera of Imperfect Fungi. Tercera edición. Minnesota; Burgess Publishing Company. +bound PAHs in fiel-contaminated sediment. Water Research: 1-13.

47. Arenas R. (2003). Micología Médica Ilustrada. Segunda edición. McGraw Hill. México. D.F. 352p.

48. Fernández L.; Rojas N.; Roldán T.; Ramírez M.; Zegarra H.; Uribe R.; Reyes R.; Flores D.; Arce M. (2006). Manual de técnicas de análisis de suelos aplicadas a la remediación de sitios contaminados. Instituto Mexicano del Petróleo Secretaría de Medio Ambiente y Recursos Naturales. Instituto Nacional de Ecología. México.179p

49. Gómez M.; Vivas L.; Ruiz R.; Reyes V.; Hurtado C. (2006). Instituto de Investigaciones Marinas y Costeras. INVEMAR. Colombia. 33p.

50. ASTM D-4006. (2012). Standard Test Method for Water in Crude Oil by Distillation. U.S.A.

51. ASTM D-4007. (2011). Standard Test Method for Water and Sediment in Crude Oil by the Centrifuge Method. U.S.A.

52. U.S.E.P.A 3500B. (1996). Organic extraction and sample preparation $5 \mathrm{~W} 84 \mathrm{E}$ test methods for evaluating solid waste; physical/ chemical methods.

53. U.S.E.P.A. (1991). Understing Biorremediation A guile forcitizens. Enviromental Protection Agency U.S.A. 185.

54. U.E.S.P.A. (1999). Use of monitored natural attenuation at superfund (USEPA) RCRA corrective action and underground storage tank sites. OSWER Directive Washington, DC. $\mathrm{N}^{\circ}$ 920p.4-17.

55. - Schwab A, Su J, Wetzel S, Pekorek S, Banks M. (1999). Extraction of petroleum hydrocarbons from soil by mechanical shaking. Environmental Science \& Technology. 33 (11):19401945.

56. Arce O.; Rodríguez V.; Rojas A. (2004). Identification of recalcitrant hydrocarbons present in a drilling waste-polluted soil. Journal Environ Science \& Health Port A. 39 (6) 1535-1545.

57. ASTM - D96 (1988). Water and Sediment in Crude Oil by Centrifuge Method. U.S.A.

58. ASTM - F1693. (1996). Standard Guide for Consideration of Bioremediation as an Oil Spill Response Method on Land. U.S.A. 
59. Cañedo V.; Ames T. (2004). Manual de laboratorio para el manejo de hongos entomopatógenos. Centro Internacional de la papa. Perú. $51 \mathrm{p}$.

60. Speighl J. (2004). Petroleum asphaltenes P1 asphaltenes, resins and the structure Of petroleum- Oil and Gas Science and Tecnology - Rev IFP, (59):5 467 - 477.

61. Mendiburu F (2015). agricolae: Statistical Procedures for Agricultural Research. R package version 1.2-3.Disponible en: https://CRAN.R-project.org/package=agricolae.

62. R Core Team. (2016). Language and environment for statistical computing. R Foundation for Statistical Computing, Vienna, Austria. Disponible en: URL https://www.R-project. org.

63. Himmelblau D. (1973). Principios y cálculos básicos de la ingeniería química. Editorial Continental. México. 23-25.

64. Rojas, V.; Salazar, A.; Arévalo, N. (2005). Biotransformación del colorante RBBR mediante el uso de dos hongos de pudrición blanca. Revista de la Sociedad de Química de México. Sociedad Química de México. 49(4) p. 179.

65. Leon, V. (1998). "Nuevos enfoques sobre la visión molecular de un crudo pesado". Visión Tecnológica, 5 (2): 131-138.

66. Peramanu S., Pruden B.; Rahimi P. (1999). "Molecular weight and specific gravity distributions for athabasca and cold lake bitumen and their saturate, aromatic, resin, and asphaltene fractions". Ind. Eng. Chem Res., 38 (8): 3121-3130.

67. Frost K.A., Daussin R.; Van Domelen, M. (2008). New, Highly Effective Asphaltene Removal System with Favorable HSE Characteristics. Halliburton. Society of Petroleum Engineers (SPE) 112420.

68. Muñoz D.; Guerrero N. (2013). Allium test para evaluar el efecto citotóxico y genotóxico de extractos naturales en células meristemáticas de Allium cepa. Memorias. (19) 11: 83-86.

69. Louisiana Department of Natural Resources. (1999). Protocolo de Louisiana 29B. Louisiana. EE.UU.

70. Godoy P.; Reina R.; Calderón A.; Wittich R.; García I.; Aranda E. (2016). Exploring the potential of fungi isolated from $\mathrm{PAH}$-polluted soil as a source of xenobiotics-degrading fungi. Environmental science and pollution research international.

71. Chosson P.; Lanau C ; Connan J. ; Dessort D. (1991). Biodegradation of refractory hydrocarbon biomarkers from petroleum under laboratory conditions. Nature 351: 640-642.

72. Radwan S.; Sorkhoh N.; Fardoun F.; Hasan R. (1995). Soil management enhancing hydrocarbon biodegradation in the polluted Kuwaiti desert. Applied Microbiology Biotechnoly 44: $265-270$.

73. Hashem A. (1995). Soil analyses and mycroflora of the Jubail Industrial City in Saudi Arabia. Journal University Kuwait Science 22: 231-237.

74. Colombo J., Cabello M., Arambarri A. 1996. Biodegradation of aliphatic and aromatics hydrocarbons by natural soil microflora and pure cultures of imperfect and lignolitic fungi. Environmental Pollution 94: 355-362.
75. Naranjo L.; Urbina H.; De Sisto A.; Leon V. (2007). Isolation of autochthonous non-white rot fungi with potential for enzymatic upgrading of Venezuelan extra-heavy crude oil. Biocatalysis and Biotransformation 25: 1-9.

76. Nkwelang G.; Kamga H.; Nkeg G.; Antai S. (2008). Studies on the diversity abundance and succession of hydrocarbon utilizing microorganisms in tropical soil polluted with oily sludge. African Journal Biotechnology 7(8):1075-1080.

77. Al-Nasrawi H. (2012). Biodegradation of crude oil by fungi isolated from Gulf of Mexico. Journal Bioremediation of Biodegradation 3:147.

78. Hasan I. (2014). Biodegradation of kerosene by Aspergillus niger and Rhizopus stolonifer. Appled. Environmental Microbiology. 2: 31-36.

79. Ali M.; Khalil M.; Abd El-Ghany. (2012). Biodegradation of some polycyclic aromatic hydrocarbons by Aspergillus terreus. African Journal Microbiology. 6: 3783-3790.

80. Chaillan F.; Le F; Fleche A.; Bury E. (2004). Identification and biodegradation potential of tropical aerobic hydrocarbon degrading microorganisms. Research. Microbiology, 155: 587-595.

81. Aranda E. (2016). Promising approaches towards biotransformation of policyclic aromatic hydrocarbons with Ascomycota fungi. Current Opinion in Biotechnology 38:1-8.

82. Pernía B.; Demey J.; Inojosa.; Naranjo-Briceño, L. (2012). Biodiversidad y potencial hidrocarbonoclástico de hongos aislados de petróleo crudo y sus derivados. Revista Latinoamericana de Biotecnología Ambiental. 3(1):1-39.

83. Uribe C, Ayala M, Perezgasga L, Naranjo L, Urbina H, Vazquez-Duhalt, R. (2011). First evidence of mineralization of petroleum asphaltenes by a strain of Neosartorya fischeri .Microbial Biotechnology. (4) 5: 663-672.

84. Hernández E.; Ramírez S.; Vazquez R. (2015). Microarray analysis of Neosartorya fischeri using different carbon sources, petroleum asphaltenes and glucose-peptone. Genomics Data. 5: 235-237.

85. Ke L.; Kun M.; Xia P.; Rui M.; Peilong Y.; Huoqing H.; Bin Y.; Xiaoyun S. (2015). Two thermophilic fungal pectinases from Neosartorya fischeri P1: Gene cloning, expression, and biochemical characterization. Journal of Molecular Catalysis B: Enzymatic. 118: 70-78.

86. Yuan, L., Loqué, D., Ye, F., Frommer, W.B.,Von Wirén, N. (2007). Nitrogen-dependent posttranscriptional regulation of the ammonium transporter AtAMT1. Journal of Plant Physiology. 143: 732-744.

87. Sarkar D.; Ferguson M.; Datta R.; Birnbaum S. (2005). Bioremediation of petroleum hydrocarbons in contaminated soils: comparison of biosolids addition, carbon supplementation, and monitored natural attenuation. Environmental Pollution (136) 1:187-95.

88. Vasconcelos U., Oliveira F.; De França F. (2011). Removal of high-molecular weight polycyclic aromatic hydrocarbons. Química. Nova 34: 218-221. 
89. Taewoo Yi, Eun-Hee Lee, Hyerim Park Y Kyung-Suk Cho. (2011). Biodegradación de hidrocarburos de petróleo por Neosartorya sp. BL4. Journal Of Environmental Science And Health. 46: 14.

90. Pinilla B Gladys, Chavarro P Bibiana, Moreno A Natalia, Navarrete O Jeannette, Muñoz M Liliana. Determinación de los genes, 16S ADNr, polA, y TpN47, en la detección de Treponema pallidum subsp. pallidum para el diagnóstico de sífilis congénita. Nova. 2015; 13 ( 24 ): 17-25.

91. Corrales Lucia Constanza, Antolinez Romero Diana Marcela, Bohórquez Macías Johanna Azucena, Corredor Vargas Aura Marcela. Bacterias anaerobias: procesos que realizan y contribuyen a la sostenibilidad de la vida en el planeta. Nova. 2015; 13( 24 ): 55-81.

92. González Yuri Lilian. Evaluación de la percepción del riesgo ocupacional en trabajadores de una empresa del sector de la construcción en Bogotá D.C. Nova. 2015; 13 ( 23 ): 93-107.

93. Carrero Sandra Helena Suescún, HerediaMontoya Dina Paola, Bolaños Yoryany Mulato, Medellín Martín Orlando Pulido. Seroprevalencia de infección por Leptospira y factores de riesgo en estudiantes de una universidad de Colombia. Nova. 2017; $15(27$ ): 131-138.

94. Jia H.; Qu L.; Wang Q. (2013). Selection of crude oil-degrading filamentous fungi and their degradation properties. Microorganisms in Environmental Management. 589-606.

95. Maddela N.; Masabanda M.; Leiva M. (2015). Novel diesel oil degrading bacteria and fungi from the Ecuadorian Amazon rainforest. Water Science and Technology. (71) 10: 1554-1561.

96. Benyahia F.; Embaby A. (2016). Bioremediation of crude oil contaminated desert soil: Effect of biostimulation, bioaugmentation and bioauailability in biopile. Treatment systems. International Journal Environmental Reseach and Public Health. 13(2):2-19.

97. Manli W.; Wrren A Dick.; Wei L.; Xiaochang W.; Quian Y.; Tingting W.; Limei X.; Minghui Z.; Liming Ch. (2016). Bioaugmentation and biostimulation of hydrocarbon degradation and the microbial community in a petroleum contamined soil. International Biodeterioration \& Biodegradation. 107: 158-164.

98. Johnsen, A.; Schmidt, S.; Hybholt, T.; Henriksen, S.; Jacobsen, C.; Andersen, O. (2007). Applied and Environmental Microbiology. 73:1474-1480.

99. Deshmukh R.; Khardenavis A.; Purohit J. (2016). Diverse Metabolic Capacities of Fungi for Bioremediation. Indian Journal of Microbiology. (56)3: 247-264.

100. Mohsenzadeh F; Shirkhani Z. (2016). Removing of Crude Oil from Polluted Areas Using the Isolated Fungi from Tehran Oil Refinery. Soil and Sediment Contamination. (25) 5:536-551.

101. Naranjo Flórez Ricardo Andrés. Avances y perspectivas en Síndrome de Asperger. Nova. 2014; 12( 21 ): 81-101.

102. Zuluaga Martha, Robledo Sebastian, Osorio-Zuluaga German A, Yathe Laura, Gonzalez Diana, Taborda Gonzalo. Metabolomics and pesticides: systematic literature review using graph theory for analysis of references. Nova. 2016; 14( 25 ): 121138.

103. Ávila de Navia Sara Lilia, Estupiñán-Torres Sandra Mónica, Díaz González Liliana. Calidad bacteriológica del agua Vereda El Charco, San Miguel de Sema, Boyacá- Colombia. Nova. 2016; 14( 25 ): 139-145. 